\title{
QTL mapping of volatile compound production in Saccharomyces cerevisiae during alcoholic fermentation
}

\author{
Matthias Eder ${ }^{1} \mathbb{D}$, Isabelle Sanchez ${ }^{1,2}$, Claire Brice ${ }^{1}$, Carole Camarasa ${ }^{1}$, Jean-Luc Legras ${ }^{1}$ and Sylvie Dequin ${ }^{1 *}$
}

\begin{abstract}
Background: The volatile metabolites produced by Saccharomyces cerevisiae during alcoholic fermentation, which are mainly esters, higher alcohols and organic acids, play a vital role in the quality and perception of fermented beverages, such as wine. Although the metabolic pathways and genes behind yeast fermentative aroma formation are well described, little is known about the genetic mechanisms underlying variations between strains in the production of these aroma compounds.

To increase our knowledge about the links between genetic variation and volatile production, we performed quantitative trait locus (QTL) mapping using 130 F2-meiotic segregants from two S. cerevisiae wine strains. The segregants were individually genotyped by next-generation sequencing and separately phenotyped during wine fermentation.

Results: Using different QTL mapping strategies, we were able to identify 65 QTLs in the genome, including 55 that influence the formation of 30 volatile secondary metabolites, 14 with an effect on sugar consumption and central carbon metabolite production, and 7 influencing fermentation parameters. For ethyl lactate, ethyl octanoate and propanol formation, we discovered 2 interacting QTLs each. Within 9 of the detected regions, we validated the contribution of 13 genes in the observed phenotypic variation by reciprocal hemizygosity analysis. These genes are involved in nitrogen uptake and metabolism (AGP1, ALP1, ILV6, LEU9), central carbon metabolism (HXT3, MAE1), fatty acid synthesis (FAS1) and regulation (AGP2, IXR1, NRG1, RGS2, RGT1, SIR2) and explain variations in the production of characteristic sensorial esters (e.g., 2-phenylethyl acetate, 2-metyhlpropyl acetate and ethyl hexanoate), higher alcohols and fatty acids.

Conclusions: The detection of QTLs and their interactions emphasizes the complexity of yeast fermentative aroma formation. The validation of underlying allelic variants increases knowledge about genetic variation impacting metabolic pathways that lead to the synthesis of sensorial important compounds. As a result, this work lays the foundation for tailoring S. cerevisiae strains with optimized volatile metabolite production for fermented beverages and other biotechnological applications.
\end{abstract}

Keywords: Yeast, Aroma compounds, Metabolites, QTL mapping, Fermentation

* Correspondence: sylvie.dequin@inra.fr

'SPO, INRA, SupAgro, Université de Montpellier, F-34060 Montpellier, France

Full list of author information is available at the end of the article

(c) The Author(s). 2018 Open Access This article is distributed under the terms of the Creative Commons Attribution 4.0 International License (http://creativecommons.org/licenses/by/4.0/), which permits unrestricted use, distribution, and reproduction in any medium, provided you give appropriate credit to the original author(s) and the source, provide a link to the Creative Commons license, and indicate if changes were made. The Creative Commons Public Domain Dedication waiver (http://creativecommons.org/publicdomain/zero/1.0/) applies to the data made available in this article, unless otherwise stated. 


\section{Background}

The aroma of fermented beverages is the result of a complex blend of volatile compounds. In wine, these volatiles originate either directly from grape must or are produced de novo by yeast during alcoholic fermentation. Yeast utilizes the nutrients contained in grape must, which are mainly hexoses, nitrogen and lipid sources, for proliferation, whereas ethanol, $\mathrm{CO}_{2}$ and various minor metabolites are produced as byproducts. Many of these metabolites are volatile with sensorial properties, which give wine its vinous character [1]. Although the flavor and aroma profile of wine is influenced by vine environment and management techniques, the choice of yeast strain plays a central role [2].

Higher alcohols and esters are the most abundant groups of fermentative aromas that are produced de novo in yeast metabolism [3]. Higher alcohols can impart a strong, pungent smell and taste when present in higher concentrations, but they result in a fruity character at low concentrations [4]. The formation of higher alcohols is carried out through decarboxylation and reduction of $\alpha$-keto acids, which derive either from central carbon metabolism or from the transamination of amino acids. Therefore, the synthesis of higher alcohols is linked to both carbon and nitrogen metabolism.

Acetate esters, which are produced by yeast from higher alcohols during fermentation, increase aroma complexity by imparting aromatic notes of pear, apple and banana to general fruitiness $[5,6]$. They are synthesized through acetyl transfer from acetyl-CoA to an alcohol by the acetyltransferases Atf1 and Atf2 [7]. Ethyl esters also contribute to global fruitiness perception and are synthesized through acyl transfer from an acyl-CoA to ethanol by the esterases Eeb1 and Eht1 [8]. The carboxylic acid molecules for ethyl ester synthesis predominantly originate from the degradation of $\alpha$-keto acids or fatty acid synthesis in lipid metabolism.

As a consequence, fermentative aroma can be seen as a complex mix of volatile compounds intimately associated with yeast metabolism. The diversity of yeast strains and variability in the regulation of yeast metabolism have a large impact on their production [9]. Even though biochemical pathways have been established for most of these compounds and major genetic determinants have been identified, the genetic basis for the variation of volatile compound production between strains remains largely unknown.

The formation of several compounds important for wine aroma has been shown to be a quantitative and complex trait, as it is influenced by the contribution of multiple genes [10]. Quantitative trait locus (QTL) mapping has been demonstrated to be a powerful approach for deciphering the genetic bases of numerous complex traits $[11,12]$ and has been applied in several biotechnological applications. From its first use in enological studies to characterize allelic variants influencing acetic acid production [13], it has been extended to decipher the genomic bases of fermentation parameters [14], the production of main metabolites and residual sugar concentrations [15], nitrogen utilization [16], sulfite production [17] and secondary fermentation [18]. QTL mapping was also used for the detection of genomic regions influencing the production of volatile compounds by yeast during wine alcoholic fermentation [10] using a population of $30 \mathrm{~F} 1$-segregants originating from a cross between an S. cerevisiae wine and a lab strain. One major QTL and seven minor genomic regions were found to influence the production of different volatile compounds despite high trait heritability. This result suggested that more analytical power is required in order to decipher the genetic bases of the production of volatiles during alcoholic fermentation. The sensitivity of QTL analysis and the ability to find loci with small contributions to phenotype variations can be increased by assessing a larger number of individuals [19]. Moreover, the resolution of the mapping can be improved and nearby QTLs can be unlinked by increasing the recombination rate of the segregants [20]. When multiple loci influence one trait, their contribution to trait variation can either be additive or interacting. Recent studies with a large yeast cross estimated that more than $40 \%$ of trait variations in a set of 20 traits could be explained by additive genetic effects, whereas pair-wise genetic interactions contributed to almost $10 \%$ of the phenotypic variance [19]. Multiple QTL mapping can not only detect linked QTLs but also provides more statistical power to find unlinked QTLs [21].

In this study, we addressed the complexity of the genetic basis underlying volatile metabolite production using a population of $130 \mathrm{~F} 2$-segregants obtained from a cross of two wine strains with different requirements for nitrogen [22]. In addition to performing a genome search for single QTLs, the large segregant population enabled us to increase the analytical strength by performing a search for multiple QTLs. As far as we know, this study is the first analysis of the interaction between loci influencing fermentative aroma formation. We identified a total of 65 QTLs in the genome that influence fermentation parameters and the production of metabolites, including 55 QTLs influencing the formation of 30 volatile secondary metabolites. For the production of ethyl lactate, ethyl octanoate and propanol, we could detect interacting QTLs. Finally, we experimentally validated the role of 13 genes in 9 of the identified genomic regions. These findings provide new information about the production of metabolites of interest due to their sensorial properties or other biotechnological value, such 
as medium chain fatty acids, fusel acids, higher alcohols and their esters. This opens new perspectives for engineering S. cerevisiae strains for broad biotechnological applications.

\section{Results and discussion Phenotyping of strains}

Using small scale fermenters, the F2-segregant population and both parental strains were phenotyped (Additional files 1 and 2) for the production of 43 extracellular metabolites that originate from nitrogen and central carbon metabolism (Fig. 1). Most traits are normally distributed among the population, indicating that they are under polygenic control (Additional file 2). One exception is the ratio of glucose to fructose after $80 \%$ of the fermentation (G/F ratio), which shows a biphasic distribution, revealing the major influence of one locus for this trait. The phenotypes of the parental strains are located within the population of segregants, indicating transgression for most traits, which can be explained by the presence of alleles with opposite impacts on these traits in the parental genomes. Although the differences between the parental strains in their need for nitrogen during fermentation were initially seen as indication of different fermentative aroma formation, a clear dependency of the production of higher alcohols, fusel acids and their esters on the parental nitrogen requirements could not be seen (Additional file 1).

Heritability of the traits was calculated according to Brem et al. (2002) [23] (Additional file 1). With a median of 70.09 and a maximum of 94.35 , the determined heritability is high, indicating reproducible phenotyping and a strong genomic influence on trait variations. For the formation of 3-methylbutanol, decanoic acid, diethyl succinate, dodecanoic acid and ethyl dodecanoate, the heritability estimate is almost zero or negative, which might be associated with insufficient analytical reproducibility. We performed a principal component analysis (PCA) to reduce the complexity of the data set for the determined secondary metabolites and to estimate the potential common regulations (Fig. 2). The first two dimensions of the PCA together explain $40.8 \%$ of global trait variance. It can be seen that several evaluated compounds are grouped according to their chemical family. The production of all higher alcohols (except propanol and 2-methylbutanol) is correlated, together with the formation of their corresponding acetate esters. The synthesis of these molecules shares a common reaction step, i.e., the decarboxylation and reduction of $\alpha$-keto acids. Another linked group of volatiles is medium chain fatty acids with their ethyl esters. These compounds share a common pathway, namely, fatty acid synthesis. Interestingly, the formation of fusel acids is not correlated to the production of higher alcohols, although both compounds are metabolized from $\alpha$-keto acids. This suggests that the reduction or oxidation reactions, which lead to the formation of these compounds from fusel aldehydes, have a strong impact. The pyruvate yield is strongly negatively correlated to the production of ethyl lactate and loosely negatively correlated to the succinate yield and the formation of diethyl succinate. Pyruvate is a metabolic intermediate of both ethyl lactate and succinate formation (Fig. 1).

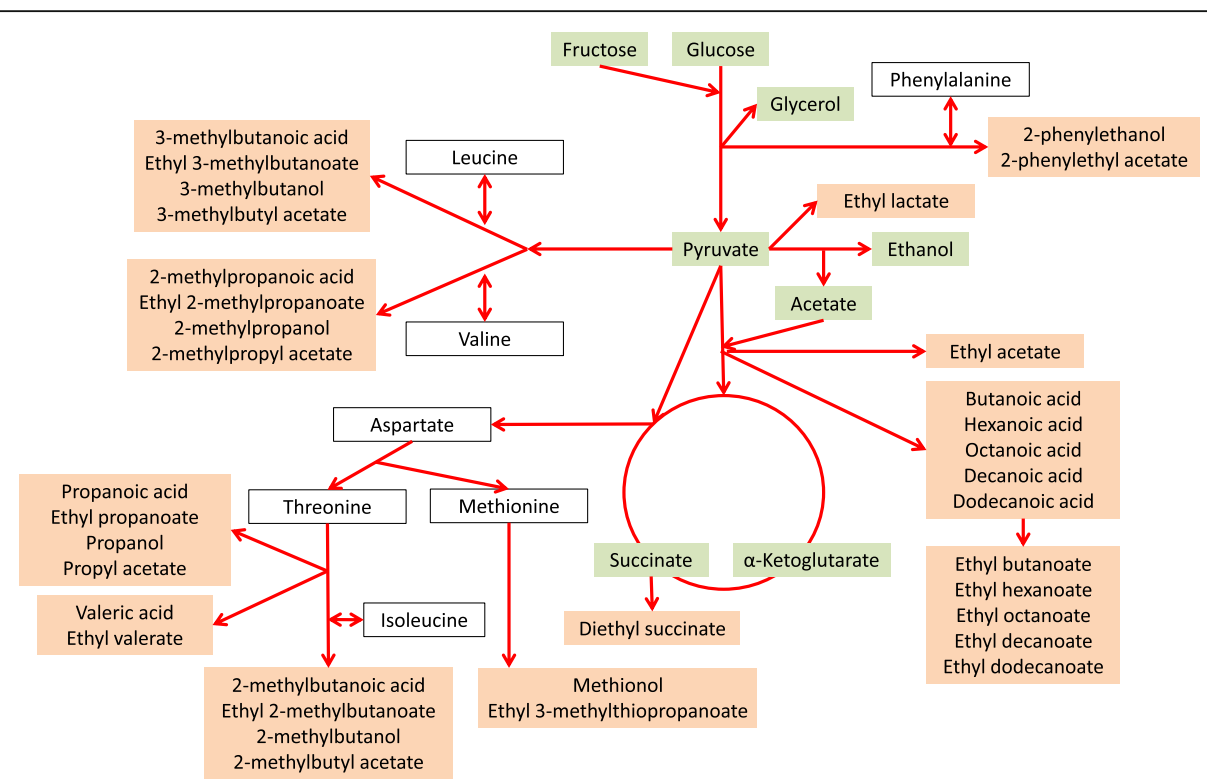

Fig. 1 Simplified synthesis pathways of determined metabolites. Main and secondary metabolites determined in this study by HPLC (green) and GC/MS (red) 


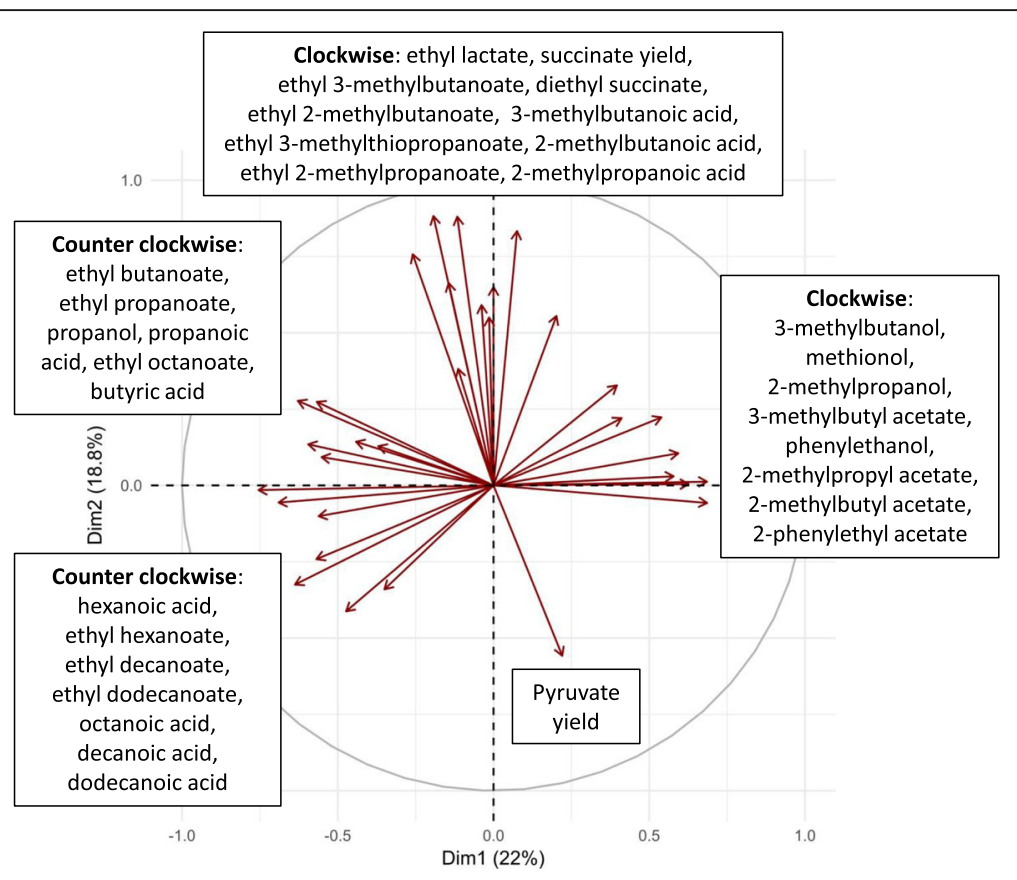

Fig. 2 Principle component analysis. PCA of the formation of extracellular metabolites by S. cerevisiae. Traits that are less than $2 \%$ explained by the first two dimensions of the PCA were excluded (2-methylbutanol, acetate yield, alpha-ketoglutarate yield, ethanol yield, ethyl acetate, glycerol yield, propyl acetate, and valeric acid)

\section{Genome-wide identification of QTLs influencing fermentation parameters, main and secondary metabolite production Simple QTL scan}

The data obtained from phenotyping and the constructed marker map were used to perform a linkage analysis on 43 quantitative traits, including fermentation parameters, the production of main metabolites and the formation of volatile secondary metabolites. We were able to find a total of 32 QTLs influencing 32 traits (Table 1). The determined logarithm of odds (LOD) scores ranged from 3.41 to 10.49 with a median of 4.35 . The highest LOD score of 10.49 was found for the influence of chr4@386.5 on the G/F ratio, which means that $32 \%$ of trait variation are explained by the QTL. The strong influence of this locus therefore accounts for the biphasic distribution of the trait. The second highest LOD score of 8.44 was found for a QTL influencing the production of a volatile compound, namely, chr11@127.6 affecting the formation of 2-methylpropanol. Six major QTL regions were detected with LOD scores greater than six for at least one trait, which corresponds to an explained trait variation of more than $20 \%$ by these loci.

Globally, these QTLs were distributed over the whole genome, with exception of chromosomes I, V, VI and VIII. The size of the identified regions ranged from $5.2 \mathrm{~kb}$ to $65.7 \mathrm{~kb}$ with a median of $33.2 \mathrm{~kb}$. The detected regions contained between 4 and 28 genes. Four
QTLs were detected for both evaluated traits of the fermentation kinetics, the fermentation time $\left(t_{80 \%}\right)$ and $\mathrm{CO}_{2}$ production rate at $\mathrm{t}_{80 \%}$. Eight QTLs were found for the concentration of extracellular main metabolites at $t_{80 \%}$. These QTLs influenced three traits, which were glycerol yield, pyruvate yield and the G/F ratio. The most QTLs were detected for the formation of volatile secondary metabolites, namely, 28 QTLs influencing the formation of 27 volatiles. This included the production of characteristic sensorial compounds, such as 2-methylbutyl acetate, 3-methylbutanol and 3-methylbutyl acetate, and industrially relevant chemicals, such as higher alcohols and organic acids.

The detected QTLs were compared with loci found in QTL mapping studies of similar traits [10, 13-15, 24]. Only QTL chr7@161.6, which influences ethyl lactate formation, co-localizes with PMA1, a plasma membrane P2-type $\mathrm{H}+$-ATPase that was shown by Abt et al. (2016) to be the responsible gene in a QTL affecting ethyl acetate production. More QTLs were in common with the findings of Rossouw et al. (2008), who used a comparative approach of combining transcriptomics and exo-metabolome analysis to predict candidate genes with a role in aroma profile modification [25]. Several of the genes proposed by Rossouw et al. (2008), e.g., ALP1, ILV6, LEU1, LEU2 and LEU9, were included in QTLs that we detected for the same or closely related traits. As the parent strains were selected because of their 
Table 1 QTLs detected with single QTL mapping. List of QTLs with an influence on fermentation parameters, the production of extracellular metabolites and volatile secondary metabolites that were detected with single QTL mapping

\begin{tabular}{|c|c|c|c|c|c|c|}
\hline & Trait & QTL name & Chromosome & Start position [bp] & End position [bp] & LOL \\
\hline \multicolumn{7}{|c|}{ Fermentation parameters } \\
\hline 8 & $\mathrm{CO}_{2}$ production rate at $\mathrm{t}_{80 \%}$ & chr4@385.5 & IV & $1,134,839$ & $1,173,812$ & 4.7 \\
\hline \multirow[t]{2}{*}{9} & $\mathrm{CO}_{2}$ production rate at $\mathrm{t}_{80 \%}$ & chr4@410.0 & IV & $1,198,692$ & $1,246,959$ & \\
\hline & $\mathrm{CO}_{2}$ production rate at $\mathrm{t}_{80 \%}$ & chr10@241.5 & $x$ & 717,987 & 726,938 & \\
\hline 20 & Fermentation time $t_{80 \%}$ & chr13@7.9 & $X I I I$ & 20,503 & 25,723 & \\
\hline 20 & $\mathrm{CO}_{2}$ production rate at $\mathrm{t}_{80 \%}$ & chr13@7.9 & $X I I I$ & 20,503 & 25,723 & \\
\hline
\end{tabular}

Extracellular metabolites after $80 \%$ of the fermentation

$\begin{array}{ll}2 & \text { Pyruvate yield } \\ 8 & \text { G/F ratio } \\ 9 & \text { G/F ratio } \\ 10 & \text { Pyruvate yield } \\ 11 & \text { Pyruvate yield } \\ 14 & \text { Pyruvate yield } \\ 20 & \text { Pyruvate yield } \\ & \text { Glycerol yield }\end{array}$

$\begin{array}{ll}\text { chr2@172.5 } & \text { II } \\ \text { chr4@386.5 } & \text { IV } \\ \text { chr4@412.2 } & \text { IV } \\ \text { chr7@20.4 } & \text { VII } \\ \text { chr7@156.9 } & \text { VII } \\ \text { chr9@58.7 } & \text { IX } \\ \text { chr13@7.9 } & \text { XIII } \\ \text { chr13@19.3 } & \text { XIII }\end{array}$

507,274
$1,153,678$
$1,205,742$
56,448
463,981
173,782
20,503
52,743

527,387

Volatile secondary metabolites after $80 \%$ of the fermentation

$\begin{array}{ll}2 & \text { Ethyl butanoate } \\ & \text { 2-methylpropanoic acid } \\ 3 & \text { Ethyl 2-methylbutanoate } \\ 4 & \text { Ethyl 2-methylpropanoate } \\ 4 & \text { Methionol } \\ 4 & \text { 3-methylbutyl acetate } \\ 5 & \text { 2-methylbutyl acetate } \\ 5 & \text { 2-phenylethyl acetate } \\ 5 & \text { 3-methylbutyl acetate } \\ 6 & \text { 2-methylbutyl acetate } \\ 6 & \text { Ethyl lactate } \\ 6 & \text { Propanoic acid } \\ 6 & \text { Propanol } \\ 10 & \text { Propyl acetate } \\ 10 & \text { Diethyl succinate } \\ 11 & \text { Ethyl 3-methylthiopropanoate } \\ & \text { Ethyl lactate } \\ 17 & \text { Dodecanoic acid } \\ 17 & \text { Dodecanoic acid } \\ 17 & \text { 2-phenylethyl acetate } \\ 17 & \text { Octanoic acid } \\ 17 & \text { Hexanoic acid } \\ 17 & \text { Ethyl hexanoate } \\ 17 & \text { 2-methylpropanylethyl acetate } \\ 17 & \end{array}$

chr2@166.4
chr3@26.1
chr4@71.3
chr4@82.9
chr4@124.6
chr4@133.6
chr4@133.6
chr4@161.9
chr4@161.9
chr4@161.9
chr4@175.0
chr4@177.5
chr4@177.5
chr4@179.4
chr7@15.0
chr7@25.5
chr7@161.6
chr7@175.5
chr7@195.5
chr7@294.6
chr11@29.5
chr11@29.5
chr11@35.5
chr11@41.8
chr11@42.5
chr11@123.8
chr11@127.6

488,757
62,518
211,091
216,058
365,865
376,106
397,927
455,335
455,335
478,242
521,776
524,924
527,398
527,398
40,689
50,239
458,995
494,396
578,880
853,536
77,969
82,548
97,410
115,238
125,453
366,406
371,345

503,880

75,040

$273,735 \quad 3.96$

$380,035 \quad 4.37$

$407,166 \quad 4.37$

$407,166 \quad 5.86$

$505,548 \quad 6.17$

$505,548 \quad 4.57$

$505,548 \quad 6.75$

$527,398 \quad 3.41$

$545,742 \quad 4.00$

$539,089 \quad 5.19$

$560,742 \quad 3.61$

$56,448 \quad 5.44$

$87,729 \quad 4.47$

$518,880 \quad 3.97$

$548,880 \quad 4.76$

$601,380 \quad 3.68$

$885,989 \quad 4.14$

$\begin{array}{ll}117,578 & 3.99\end{array}$

$115,238 \quad 6.94$

115,238

$145,211 \quad 4.29$

$132,044 \quad 4.29$

$391,690 \quad 6.63$

$400,712 \quad 8.44$ 
Table 1 QTLs detected with single QTL mapping. List of QTLs with an influence on fermentation parameters, the production of extracellular metabolites and volatile secondary metabolites that were detected with single QTL mapping (Continued)

\begin{tabular}{|c|c|c|c|c|c|c|}
\hline & Trait & QTL name & Chromosome & Start position [bp] & End position [bp] & LOD Score \\
\hline 18 & 3-methylbutanol & chr11@132.7 & $X I$ & 380,437 & 403,181 & 3.56 \\
\hline \multirow[t]{2}{*}{18} & 2-methylpropanoic acid & chr11@134.4 & $X I$ & 400,712 & 405,331 & 4.64 \\
\hline & 2-methylpropanol & chr11@158.4 & $X I$ & 470,852 & 477,578 & 3.80 \\
\hline 19 & Propyl acetate & chr12@222.6 & $X \|$ & 662,035 & 699,182 & 4.83 \\
\hline \multirow[t]{2}{*}{19} & Propanol & chr12@226.9 & $X \|$ & 662,035 & 691,268 & 4.08 \\
\hline & Valeric acid & chr13@102.0 & $X I I I$ & 296,288 & 312,983 & 5.87 \\
\hline 21 & Propanoic acid & chr14@41.9 & XIV & 119,900 & 146,614 & 4.67 \\
\hline 21 & Propanol & chr14@43.9 & XIV & 119,900 & 146,614 & 7.03 \\
\hline 21 & Propyl acetate & chr14@46.9 & XIV & 124,114 & 150,370 & 6.19 \\
\hline \multirow[t]{4}{*}{21} & Valeric acid & chr14@48.9 & XIV & 125,823 & 150,370 & 7.72 \\
\hline & Propanoic acid & chr14@58.9 & XIV & 160,420 & 185,626 & 3.83 \\
\hline & Valeric acid & chr14@81.8 & XIV & 233,520 & 259,114 & 3.88 \\
\hline & Ethyl 3-methylbutanoate & chr15@77.3 & $X V$ & 212,898 & 239,482 & 3.76 \\
\hline 22 & Ethyl decanoate & chr15@139.0 & $X V$ & 409,364 & 431,700 & 3.97 \\
\hline 22 & Ethyl octanoate & chr15@142.3 & $X V$ & 414,810 & 438,628 & 5.02 \\
\hline 23 & 3-methylbutanoic acid & chr15@162.7 & $X V$ & 485,607 & 511,993 & 4.29 \\
\hline \multirow[t]{3}{*}{23} & 2-phenylethyl acetate & chr15@176.5 & $X V$ & 511,993 & 545,871 & 3.56 \\
\hline & Diethyl succinate & chr15@297.3 & $X V$ & 879,033 & 901,450 & 4.46 \\
\hline & 3-methylbutanoic acid & chr16@191.9 & $\mathrm{XVI}$ & 552,371 & 593,439 & 3.83 \\
\hline 25 & Diethyl succinate & chr16@303.9 & $\mathrm{XVl}$ & 899,570 & 920,003 & 4.08 \\
\hline 25 & Ethyl 3-methylbutanoate & chr16@303.9 & $\mathrm{XVl}$ & 904,961 & 917,224 & 3.81 \\
\hline 25 & Ethyl 2-methylbutanoate & chr16@304.1 & $\mathrm{XVl}$ & 904,961 & 917,224 & 3.79 \\
\hline
\end{tabular}

Single traits that are influenced by the same QTL (under the condition that the distance between detected peaks is less than $10 \mathrm{cM}$; in combination with Table 2) are indicated with superscript numbers in the left column of the table

different need for nitrogen during fermentation, we compared the detected QTLs with genomic regions found by Brice et al. (2014) to influence nitrogen requirement using the same parental strains [16]. No match could be seen for QTLs influencing fermentative aroma formation and nitrogen requirement, which could possibly be explained by the differences in fermentation conditions.

\section{Double and multiple QTL scan}

To search for additional minor QTLs and to assess genetic interactions between our detected regions, we performed a two-dimensional, two-QTL scan and a multiple QTL search for all traits. The analyses confirmed 24. QTLs that were already found with the single QTL mapping and proposed 36 additional loci (Table 2). With the double QTL mapping, we found significant evidence for an interacting QTL pair at positions chr10@88.5 and chr11@51.7, influencing the formation of ethyl octanoate and accounting for $10.29 \%$ of trait variation. Another interacting QTL pair, chr2@181.0 and chr16@304.0,was found to influence the production of ethyl lactate, explaining $10.17 \%$ of trait variation. Multiple QTL mapping proposed interacting regions for a wide range of traits. However, their contributions to the respective phenotypes were low, with LOD scores of generally less than two. Due to penalization of the LOD score for more complex models of interaction, solely additive models were found to be more significant for all traits. This indicates that our number of segregants was still insufficient to achieve the statistical power required for the determination of QTL interactions. However, for the production of propanol the three involved QTLs, chr4@176.9, chr12@233.1 and chr14@45.8, could be detected with all three mapping strategies, giving strong evidence for their validity. Although models consisting of viewer QTLs were seen to be more probable by the multiple QTL mapping, the most likely model containing all three loci was an additive model with an interaction between chr4@176.9 and chr12@233.1. This indicates a remaining probability for the proposed interaction, which was calculated to potentially account for $5.58 \%$ of trait variation.

Combining the results from the single and multiple QTL mapping, each trait is influenced by a median of 3 QTLs, ranging from 1 to 7 . The best explained trait is 
Table 2 QTLs detected with double and multiple QTL mapping. QTLs with an influence on fermentation parameters and the production of extracellular metabolites and volatile secondary metabolites that were additionally detected with double and multiple QTL searches

\begin{tabular}{|c|c|c|c|c|c|}
\hline & Trait & QTL name & Chromosome & Peak [bp] & LOD Score \\
\hline & Diethyl succinate & chr1@64.7 & I & 194,100 & 4.23 \\
\hline 1 & Ethyl 2-methylbutanoate & chr2@116.2 & $\|$ & 348,600 & 4.13 \\
\hline 1 & Hexanoic acid & chr2@122.1 & $\|$ & 366,300 & 2.54 \\
\hline \multirow[t]{2}{*}{2} & Ethyl lactate & chr2@181.0 & $\|$ & 543,000 & 4.78 \\
\hline & Ethyl 2-methylpropanoate & chr3@78.8 & III & 236,400 & 2.84 \\
\hline 3 & Pyruvate yield & chr4@91.9 & IV & 275,730 & 2.39 \\
\hline 3 & Ethyl butanoate & chr4@92.0 & IV & 275,985 & 3.63 \\
\hline 4 & Ethyl hexanoate & chr4@132.0 & IV & 396,000 & 2.59 \\
\hline 5 & 2-methylpropyl acetate & chr4@165.8 & IV & 497,400 & 2.42 \\
\hline 6 & Diethyl succinate & chr4@175.0 & IV & 525,000 & 2.99 \\
\hline \multirow[t]{3}{*}{6} & Ethyl octanoate & chr4@175.0 & IV & 525,000 & 2.14 \\
\hline & Dodecanoic acid & chr4@298.0 & IV & 894,000 & 4.60 \\
\hline & Valeric acid & chr4@324.9 & IV & 974,700 & 2.50 \\
\hline 7 & 2-methylpropanol & chr4@348.9 & IV & $1,046,700$ & 3.36 \\
\hline 7 & 3-methylbutanol & chr4@348.9 & IV & $1,046,730$ & 3.66 \\
\hline \multirow[t]{3}{*}{9} & Pyruvate yield & chr4@411.9 & IV & $1,235,730$ & 2.54 \\
\hline & $\mathrm{G} / \mathrm{F}$ ratio & chr6@62.0 & $\mathrm{VI}$ & 186,000 & 3.90 \\
\hline & Ethyl 3-methylbutanoate & chr6@85.2 & $\mathrm{Vl}$ & 255,600 & 4.14 \\
\hline 12 & Decanoic acid & chr7@198.0 & VII & 594,000 & 3.65 \\
\hline 13 & 2-methylpropyl acetate & chr9@16.9 & IX & 50,700 & 2.09 \\
\hline \multirow[t]{2}{*}{13} & Dodecanoic acid & chr9@17.6 & IX & 52,800 & 3.20 \\
\hline & 2-methylbutyl acetate & chr9@32.6 & IX & 97,800 & 1.75 \\
\hline 14 & Dry weight & chr9@60.0 & IX & 180,066 & 3.67 \\
\hline 14 & Ethyl propanoate & chr9@67.5 & IX & 202,500 & 2.88 \\
\hline \multirow[t]{3}{*}{14} & Propanol & chr9@67.5 & IX & 202,500 & 1.85 \\
\hline & 2-phenylethyl acetate & chr9@101.1 & IX & 303,300 & 2.25 \\
\hline & Propyl acetate & chr10@27.2 & $x$ & 81,600 & 1.53 \\
\hline 15 & Ethyl hexanoate & chr10@61.3 & $x$ & 183,900 & 2.97 \\
\hline \multirow[t]{3}{*}{15} & Hexanoic acid & chr10@61.3 & $x$ & 183,900 & 2.78 \\
\hline & Ethyl octanoate & chr10@88.5 & $x$ & 265,500 & 5.24 \\
\hline & Propanol & chr10@104.7 & $x$ & 314,100 & 2.08 \\
\hline 16 & 2-methylpropanol & chr10@213.1 & $x$ & 639,300 & 2.29 \\
\hline 16 & 2-methylpropyl acetate & chr10@221.7 & $x$ & 665,100 & 4.04 \\
\hline 16 & 2-methylbutyl acetate & chr10@228.1 & $x$ & 684,300 & 2.34 \\
\hline 16 & 3-methylbutyl acetate & chr10@228.8 & $x$ & 686,400 & 2.97 \\
\hline 17 & Decanoic acid & chr11@29.2 & $X I$ & 87,600 & 3.95 \\
\hline 17 & Ethyl decanoate & chr11@34.2 & $X I$ & 102,438 & 2.65 \\
\hline 17 & $t_{80 \%}$ & chr11@43.2 & $X I$ & 129,600 & 3.10 \\
\hline \multirow[t]{4}{*}{17} & Ethyl octanoate & chr11@51.7 & $X I$ & 155,100 & 4.95 \\
\hline & Glycerol yield & chr11@70.0 & $X I$ & 210,000 & 2.72 \\
\hline & G/F ratio & chr11@85.6 & $X I$ & 256,800 & 2.65 \\
\hline & Ethyl propanoate & chr11@107.7 & $X I$ & 323,100 & 3.78 \\
\hline
\end{tabular}


Table 2 QTLs detected with double and multiple QTL mapping. QTLs with an influence on fermentation parameters and the production of extracellular metabolites and volatile secondary metabolites that were additionally detected with double and multiple QTL searches (Continued)

\begin{tabular}{|c|c|c|c|c|c|}
\hline & Trait & QTL name & Chromosome & Peak [bp] & LOD Score \\
\hline \multirow[t]{9}{*}{$\overline{18}$} & 3-methylbutanoic acid & chr11@134.4 & $X \mid$ & 403,170 & 3.68 \\
\hline & 2-methylpropyl acetate & chr12@98.3 & $X \|$ & 294,900 & 3.15 \\
\hline & Ethyl 2-methylbutanoate & chr12@123.8 & $\mathrm{XII}$ & 371,400 & 3.34 \\
\hline & Ethyl propanoate & chr12@139.6 & $X \|$ & 418,800 & 3.67 \\
\hline & $\mathrm{CO}_{2}$ production rate at $\mathrm{t}_{80 \%}$ & chr12@257.3 & $X \|$ & 771,900 & 2.47 \\
\hline & 2-methylpropanol & chr12@317.1 & $\mathrm{XII}$ & 951,300 & 3.08 \\
\hline & G/F ratio & chr13@164.5 & XIII & 493,500 & 4.99 \\
\hline & Propyl acetate & chr13@248.3 & $X I I I$ & 744,900 & 2.11 \\
\hline & 2-phenylethyl acetate & chr13@304.0 & $X I I I$ & 912,000 & 2.55 \\
\hline \multirow[t]{2}{*}{21} & Dodecanoic acid & chr14@36.3 & XIV & 108,900 & 4.69 \\
\hline & Ethyl 3-methylthiopropanoate & chr14@227.0 & XIV & 681,000 & 3.42 \\
\hline 22 & 2-phenylethanol & chr15@132.0 & $x V$ & 396,000 & 1.62 \\
\hline \multirow[t]{5}{*}{23} & 2-methylbutyl acetate & chr15@172.0 & $X V$ & 516,000 & 2.55 \\
\hline & Ethyl hexanoate & chr15@265.4 & $X V$ & 796,200 & 4.47 \\
\hline & Ethyl 3-methylbutanoate & chr15@304.4 & $X V$ & 913,200 & 2.77 \\
\hline & 2-methylpropanoic acid & chr15@314.4 & $X V$ & 943,200 & 2.95 \\
\hline & 2-phenylethyl acetate & chr15@352.0 & $X V$ & $1,056,000$ & 2.85 \\
\hline 24 & 2-methylpropanol & chr16@13.8 & 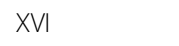 & 41,400 & 4.06 \\
\hline 24 & 2-methylbutyl acetate & chr16@16.4 & $X \mathrm{VI}$ & 49,200 & 2.78 \\
\hline \multirow[t]{2}{*}{24} & $\mathrm{G} / \mathrm{F}$ ratio & chr16@18.3 & $X \mathrm{VI}$ & 54,900 & 2.75 \\
\hline & Valeric acid & chr16@116.5 & $X \mathrm{Vl}$ & 349,500 & 2.04 \\
\hline 25 & Ethyl lactate & chr16@304.0 & $X \mathrm{~V} I$ & 912,000 & 7.00 \\
\hline
\end{tabular}

Single traits that are influenced by the same QTL (under the condition that the distance between detected peaks is less than $10 \mathrm{cM}$; in combination with Table 1 ) are indicated with superscript numbers in the left column of the table

the G/F ratio with 6 detected loci accounting for $61.0 \%$ of determined trait variation. Regarding volatile formation, the difference in 2-methylpropanol production can be best elucidated, with 6 identified QTLs explaining $54.5 \%$ of trait variation. Several QTLs display pleiotropic effects, as they influence many traits and can therefore be considered "hotspots". The region affecting the most traits is chrXI:77,969..155,100, which influences the fermentation time $\left(t_{80 \%}\right)$ and the formation of eight volatile compounds, namely, hexanoic acid, octanoic acid, decanoic acid, and their corresponding ethyl esters as well as ethyl dodecanoate and 2-phenylethyl acetate. Twenty-four other QTLs were found to influence more than one trait. This is often the case for the production of related compounds and indicates common regulation, which was already concluded by PCA. Examples for jointly influenced traits are sugar consumption and the $\mathrm{CO}_{2}$ production rate, pyruvate yield and the formation of ethyl esters, the production of 2-methylpropanol and 3-methylbutanol, and the formation of several acetate esters.
Validation of genomic regions involved in metabolic traits For the validation of single QTLs and the identification of impacting allelic variants within the corresponding regions, 19 genes in 10 QTLs were further evaluated using RHA (Table 3). These target genes were chosen since they contained non-synonymous SNPs between the parent cells and were suspected to play a role in the detected traits, as their biologic functions were mostly connected to central carbon metabolism or nitrogen uptake and metabolism. In 9 QTLs, we could identify 13 genes that influence hexose transport, $\mathrm{CO}_{2}$ production rate and the formation of medium chain fatty acids, fusel acids, higher alcohols, and their corresponding esters (Table 3).

\section{Hexose transporter Hxt3 influences sugar utilization}

Hexose transport is a limiting step for alcoholic fermentation speed [26]. QTL chr4@386.5, which influences the $\mathrm{CO}_{2}$ production rate and $\mathrm{G} / \mathrm{F}$ ratio, contains three hexose transporter genes, HXT3, HXT6 and HXT7. We evaluated these genes individually by RHA. As the 
Table 3 Validated allelic variants in detected QTLs. Selected target genes for the validation of QTLs influencing fermentation kinetics, substrate consumption and the production of fermentative aromas; differences caused by the allelic gene variants regarding the influenced traits were detected by RHA and are given as the ratio of phenotype MTF2621 to phenotype MTF2622

\begin{tabular}{|c|c|c|c|}
\hline QTL name & Trait & Evaluated genes & $\begin{array}{l}\text { Different impact of allele on trait as } \\
\text { MTF2621/MTF2622 [factor] }\end{array}$ \\
\hline chr2@166.4 & $\begin{array}{l}\text { Ethyl butanoate } \\
\text { Ethyl lactate } \\
\text { Pyruvate yield }\end{array}$ & $A G P 2$ & $0.79^{* * *}$ ethyl lactate \\
\hline \multirow[t]{2}{*}{ chr3@26.1 } & \multirow[t]{2}{*}{ 2-methylpropanoic acid } & $A G P 1$ & $1.26^{*} 2$-methylpropanoic acid \\
\hline & & ILV6 & no effect \\
\hline chr4@71.3 & $\begin{array}{l}\text { Ethyl 2-methylbutanoate } \\
\text { Ethyl butanoate } \\
\text { Ethyl 2-methylpropanoate } \\
\text { Pyruvate yield }\end{array}$ & YDL124W & no effect \\
\hline chr4@133.6 & $\begin{array}{l}\text { 2-methylbutyl acetate } \\
\text { 3-methylbutyl acetate } \\
\text { Ethyl hexanoate } \\
\text { Methionol }\end{array}$ & SIR2 & $\begin{array}{l}0.77^{*} 3 \text {-methylbutyl acetate } \\
0.78^{* *} \text { ethyl hexanoate }\end{array}$ \\
\hline chr4@177.5 & $\begin{array}{l}\text { Ethyl lactate } \\
\text { Ethyl octanoate } \\
\text { Diethyl succinate } \\
\text { Propanoic acid } \\
\text { Propanol } \\
\text { Propyl acetate }\end{array}$ & $N R G 1$ & 1.10* propanol \\
\hline \multirow[t]{4}{*}{ chr4@386.5 } & $\mathrm{CO}_{2}$ production rate at $\mathrm{t}_{80 \%}$ & HXT3 & $1.07^{*} \mathrm{CO}_{2}$ production rate \\
\hline & \multirow[t]{3}{*}{ G/F ratio } & & $1.86^{* *} \mathrm{G} / \mathrm{F}$ ratio \\
\hline & & HXT6 & no effect \\
\hline & & HXT7 & no effect \\
\hline \multirow[t]{4}{*}{ chr11@29.5 } & \multirow{4}{*}{$\begin{array}{l}\text { 2-phenylethyl acetate } \\
\text { Ethyl decanoate } \\
\text { Ethyl dodecanoate } \\
\text { Ethyl hexanoate } \\
\text { Ethyl octanoate } \\
\text { Decanoic acid } \\
\text { Hexanoic acid } \\
\text { Octanoic acid } \\
\text { t }_{80 \%}\end{array}$} & $A C P 1$ & no effect \\
\hline & & FAS1 & $\begin{array}{l}0.81^{* *} \text { ethyl hexanoate } \\
0.82^{* *} \text { decanoic acid } \\
0.84^{* *} \text { hexanoic acid } \\
0.89^{* *} \text { octanoic acid }\end{array}$ \\
\hline & & FAT3 & no effect \\
\hline & & PXA2 & no effect \\
\hline \multirow[t]{3}{*}{ chr11@127.6 } & \multirow{3}{*}{$\begin{array}{l}\text { 2-methylpropanoic acid } \\
\text { 2-methylpropanol } \\
\text { 2-methylpropyl acetate } \\
\text { 3-methylbutanoic acid } \\
\text { 3-methylbutanol }\end{array}$} & $\mid X R 1$ & $\begin{array}{l}1.14^{* *} \text { 2-methylpropanol } \\
1.16^{*} \text { 2-methylpropanoic acid }\end{array}$ \\
\hline & & MAE1 & $\begin{array}{l}1.43^{* *} \text { 2-methylpropanoic acid } \\
1.67^{* * *} \text { 2-methylpropanol } \\
1.27^{* * *} \text { 3-methylbutanoic acid } \\
1.40^{*} \text { 3-methylbutanol }\end{array}$ \\
\hline & & RGT1 & $1.15^{* * *} 2$-methylpropanol \\
\hline chr12@226.9 & $\begin{array}{l}\text { Propanol } \\
\text { Propyl acetate }\end{array}$ & whole region & no effect \\
\hline chr14@48.9 & $\begin{array}{l}\text { Dodecanoic acid } \\
\text { Propanoic acid } \\
\text { Propanol } \\
\text { Propyl acetate } \\
\text { Valeric acid }\end{array}$ & $A L P 1$ & $\begin{array}{l}0.90^{*} \text { dodecanoic acid } \\
1.07^{* *} \text { propanol } \\
1.26^{* * *} \text { valeric acid }\end{array}$ \\
\hline \multirow[t]{2}{*}{ chr15@176.5 } & \multirow{2}{*}{$\begin{array}{l}\text { 2-methylbutyl acetate } \\
\text { 2-phenylethyl acetate } \\
\text { 3-methylbutanoic acid }\end{array}$} & LEU9 & 1.08* 2-phenylethyl acetate \\
\hline & & RGS2 & $\begin{array}{l}1.21^{*} \text { 2-methylbutyl acetate } \\
0.83^{*} \text { 2-phenylethyl acetate }\end{array}$ \\
\hline
\end{tabular}

$\left(p\right.$-value: ns (not significant) $\left.>0.05,{ }^{*} \leq 0.05,{ }^{* *} \leq 0.01,{ }^{* * *} \leq 0.001\right)$

sequences of HXT6 and HXT7 are nearly identical, we assessed the effect of both genes together. Variation in $H X T 3$ was found as the sole effect influencing the $\mathrm{CO}_{2}$ production rate and the $\mathrm{G} / \mathrm{F}$ ratio (Additional file 3 ). The MTF2621 allele of the gene increased the $\mathrm{CO}_{2}$ production rate by a factor of 1.07 and increased the G/F 
ratio by a factor of 1.86. An effect of this allelic variation on the production of determined volatiles could not be detected. A variant of HXT3 has already been described in the literature by Guillaume et al. (2007) to have a higher affinity for fructose [27] and was detected among flor strains [28]. This variant originated through recombination between the orthologs HXT1 and HXT3. Except for SNP T1411A, which results in amino acid change L471I, the MTF2621 allele of HXT3 is identical to the variant described by Guillaume et al. (2007). We can therefore suggest that the allelic variants of HXT3 are the driving factor behind the biphasic distribution of the G/F ratio among the segregants.

\section{The formation of medium chain fatty acids and their ethyl} esters is influenced by Agp2, Fas 1 and Sir2

Ethyl esters of medium chain fatty acids provide floral and fruity notes to fermented beverages. In QTL chr4@133.6 and QTL hotspot chr11@29.5, which influence the formation of medium chain fatty acids and their ethyl esters, we identified SIR2 and FAS1 as causative genes (Table 3). In chr2@166.4, a QTL impacting ethyl butanoate production with a lower significance (LOD 3.96), AGP2 was found to modulate the formation of butanoic acid, the substrate for ethyl butanoate.

Fatty acids are synthesized from the repeated condensation of malonyl-CoA and acetyl-CoA, which is carried out by fatty acid synthetase (FAS). The FAS complex consists of the beta subunit Fas1 and the alpha subunit Fas2 [29]. Fas1, which was found to regulate the expression of FAS2 [30], possesses four independent enzymatic functions, i.e., acetyl transferase, enol reductase, dehydratase and malonyl/palmitoyl transferase [31]. The parental allelic variants of FAS1 differ in three non-synonymous SNPs (Table 4), of which one, SNP I1970V, lies in the malonyl-CoA-acyl carrier protein transacylase domain of the protein. The MTF2621 allele of Fas1 causes a significant decrease in the formation of hexanoic acid, ethyl hexanoate, valeric acid, octanoic acid, decanoic acid and dodecanoic acid by a factor of $0.78-0.89$ (Fig. 3). Therefore, we can suggest that the MTF2621 allele of FAS1 is less active than the MTF2622 allele, and thus leads to a decreased synthesis rate of fatty acids.

The gene SIR2 encodes an NAD +-dependent deacetylase involved in chromatin silencing [32]. The allelic variants of SIR2 differ in two non-synonymous SNPs (Table 4). The MTF2621 allele of the gene causes a decrease in the formation of hexanol, octanoic acid, decanoic acid, dodecanoic acid, ethyl butanoate and ethyl hexanoate up to a factor of 0.57 (Fig. 3). In addition, the extracellular concentration of acetate was decreased by a factor of 0.8 (Additional file 3). Sir2 was found to influence the expression of the acetyl-CoA synthase ACS2 [33], and a
Table 4 Non synonymous SNPs between allelic variants. Differences in the amino acid (AA) sequence of the expressed protein resulting from non-synonymous SNPs between the allelic variants of the evaluated target genes. Comparison of the strains MTF2621 and MTF2622 with the S. cerevisiae reference strain S288C

\begin{tabular}{|c|c|c|c|c|}
\hline Gene & AA position & S288C & MTF2621 & MTF2622 \\
\hline \multirow[t]{8}{*}{$A G P 1$} & 7 & $P$ & $P$ & L \\
\hline & 24 & G & $\mathrm{E}$ & G \\
\hline & 142 & $N$ & $S$ & $\mathrm{~N}$ \\
\hline & 316 & V & V & A \\
\hline & 370 & $F$ & $\mathrm{~L}$ & $F$ \\
\hline & 466 & I & $L$ & 1 \\
\hline & 540 & $\mathrm{~L}$ & 1 & L \\
\hline & 597 & $\mathrm{D}$ & $N$ & D \\
\hline$A G P 2$ & 256 & $\mathrm{H}$ & Y & $\mathrm{H}$ \\
\hline ALP1 & 126 & V & V & A \\
\hline \multirow[t]{3}{*}{ FAS1 } & 1504 & V & A & V \\
\hline & 1715 & V & A & V \\
\hline & 1970 & V & 1 & V \\
\hline \multirow[t]{2}{*}{ ILV6 } & 4 & $\mathrm{~S}$ & $\mathrm{~L}$ & S \\
\hline & 56 & A & P & A \\
\hline \multirow[t]{6}{*}{$\mid X R 1$} & 45 & $\mathrm{~T}$ & $\mathrm{~T}$ & A \\
\hline & 65 & Q & Q & - \\
\hline & 93 & Y & Y & $\mathrm{F}$ \\
\hline & 104 & - & ATाTाT & - \\
\hline & 291 & M & M & L \\
\hline & 570 & QQ & $\mathrm{QQ}$ & - \\
\hline \multirow[t]{2}{*}{ LEU9 } & 76 & $\mathrm{D}$ & $D$ & $\mathrm{H}$ \\
\hline & 176 & $\mathrm{~S}$ & $S$ & Y \\
\hline MAE1 & 605 & I & 1 & V \\
\hline \multirow[t]{2}{*}{$N R G 1$} & 129 & $P$ & $\mathrm{H}$ & P \\
\hline & 156 & $\mathrm{~T}$ & $S$ & $\mathrm{~T}$ \\
\hline RGS2 & 99 & Y & $N$ & Y \\
\hline \multirow[t]{4}{*}{ RGT1 } & 326 & $\mathrm{~L}$ & $\mathrm{~L}$ & $P$ \\
\hline & 717 & I & I & V \\
\hline & 722 & $P$ & P & A \\
\hline & 729 & $S$ & $S$ & $\mathrm{~N}$ \\
\hline \multirow[t]{2}{*}{ SIR2 } & 178 & Q & Q & $\mathrm{H}$ \\
\hline & 201 & $S$ & G & S \\
\hline
\end{tabular}

regulating function by Sir2 on the activity of acetyl-CoA synthase enzymes by deacetylation was proposed by Starai et al. (2003) [34]. Furthermore, Casatta et al. (2013) demonstrated that a null mutant of SIR2 showed increased acetate metabolism and a lower excretion of acetate to the medium [35]. Based on our observations, we can therefore suggest that the MTF2621 variant of Sir2 has lower 


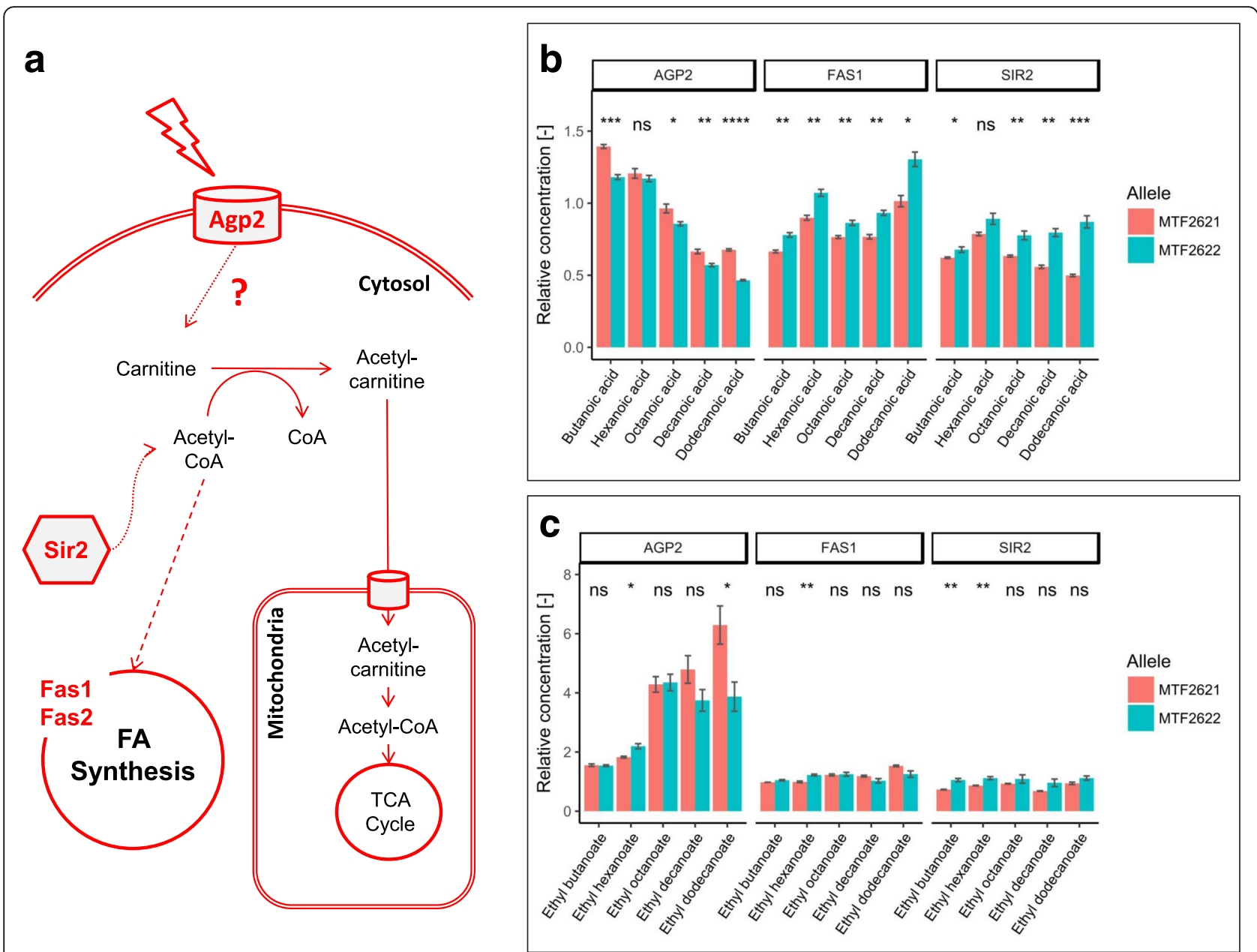

Fig. 3 Effect of validated variants on medium chain fatty acid formation. Simplified pathway of fatty acid synthesis by the enzymes Fas 1 and Fas2, which is dependent on intracellular acetyl transport (a). Allelic effect of the enzymes Agp2, Fas1 and Sir2 on the formation of fatty acids (b) and fatty acid ethyl esters (c) as determined by RHA. Concentrations are given in relation to the heterozygote of the parental strains MTF2621 and MTF2622. ( $p$-value: ns (not significant) $>0.05,{ }^{*} \leq 0.05,{ }^{* *} \leq 0.01,{ }^{* * *} \leq 0.001,{ }^{* * * *} \leq 0.0001$ )

deacetylase activity compared to the other variant, which results in decreased expression of $A C S 2$ and reduced activation of acetyl-CoA synthases. Consequently, this reduced activity leads to a lower availability of acetate and acetylCoA for fatty acid synthesis and elongation.

Other small but significant influences of SIR2 can be seen in the formation of 2-methylpropanol, 3-methylbutanol and other degradation products of $\alpha$-keto acids, with the MTF2621 allele leading to a decrease of these compounds (Fig. 4). Sir2 was found to modulate the expression of the amino acid permease AGP1 [36]. Altered expression of AGP1 could impact the nitrogen assimilation and thus the formation of amino acid related fermentative aromas. Furthermore, as Sir2 is dependent on the cofactor NAD+, its altered activity could influence redox homeostasis of the cell. Redox imbalances were reported to significantly affect the production of fermentative aromas by S. cerevisiae [37].
AGP2 encodes a plasma membrane protein that is involved in the uptake of carnitine and polyamines $[38,39]$. Carnitine is important for intracellular acetyl transport between cellular compartments [40], and the level of carnitine can therefore affect the availability of acetyl-CoA for fatty acid synthesis. However, carnitine is not present in the synthetic medium used in this study. Agp2 positively regulates the expression of various proteins involved in substrate transport and other biological processes, and might also act as a sensor of environmental signals [41]. One non-synonymous SNP was found to distinguish the two parental variants (Table 4 ), and it is located in the extracellular region of the protein. The MTF2621 allele of AGP2 causes an increase in the formation of butanoic acid, decanoic acid, dodecanoic acid and ethyl dodecanoate up to a factor of 1.63 (Fig. 3). We suggest that the reported 

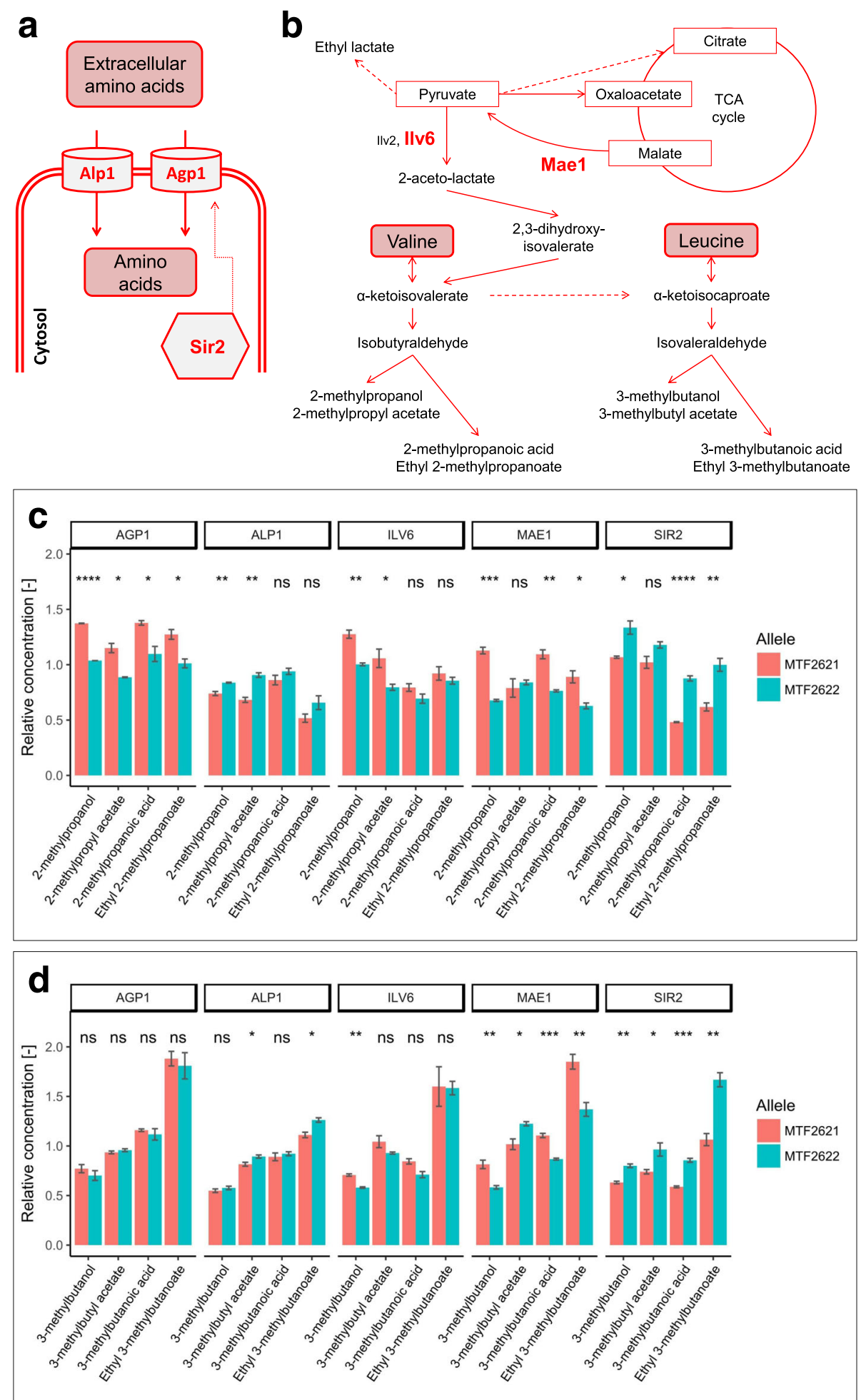

Fig. 4 Effect of validated variants on of higher alcohol and fusel acid formation. Amino acids are transported into the cell by Agp1 and Alp1. The expression of AGP1 is influenced by Sir2 (a). Simplified synthesis pathway of fermentative aromas connected to valine and leucine metabolism (b). Allelic effect of the involved enzymes Agp1, Alp1, Ilv6, Mae1 and Sir2 on the formation of volatiles deriving from a-ketoisovalerate (c) and a-ketoisocaproate (d) as determined by RHA. Concentrations are given in relation to the heterozygote of the parental strains MTF2621 and MTF2622. ( $p$-value: ns (not significant) $>0.05,{ }^{*} \leq 0.05,{ }^{* *} \leq 0.01,{ }^{* *} \leq 0.001,{ }^{* * *} \leq 0.0001$ ) 
SNP in AGP2 causes a higher formation rate of fatty acids for MTF2621, although the causative function remains unclear.

\section{The formation of higher alcohols, fusel acids and their esters is influenced by Agp1, Ilv6, Mae1}

Higher alcohols, fusel acids and especially their esters are essential fermentative aroma components that provide notes ranging from fruity to flowery. We identified MAE1 in chr11@127.6, the QTL with the highest LOD score for volatile compounds, which influences the formation of five higher alcohols, fusel acids and acetate esters (Table 3). The enzyme Mae1 catalyzes the oxidative decarboxylation of malate to pyruvate [42]. Pyruvate is a precursor for the synthesis of the amino acids alanine, isoleucine, leucine and valine [43]. An intermediate of valine and leucine biosynthesis, $\alpha$-ketoisovalerate, can also be degraded to 2-methylpropanol and 2-methylpropanoic acid or to 3-methylbutanol and 3-methylbutanoic acid via $\alpha$-ketoisocaproate (Fig. 4). The allelic variants of MAE1 differ in one non-synonymous SNP (Table 4), which is located in the NAD-binding domain of the protein. Furthermore, 5 SNPs in the 1000-bp upstream region of the gene affect predicted binding motifs for the proteins Azf1, Mot3, Rtg1, Rtg3, Stp1 and Stp2 (Additional file 4). The hemizygote carrying only the MTF2621 allele of MAE1 shows increased formation of 2-methylpropanol, 3-methylbutanol, 2-methylpropanoic acid and 3-methylbutanoic acid by up to a factor of 1.67 (Fig. 4). We can suggest that the MTF2621 allele of MAE1 is superior to the MTF2622 allele and induces an increased flux of malate to pyruvate, leading to higher formation of $\alpha$-keto acids and their degradation products. This proposal is further supported by an observed increased formation of ethyl lactate (Additional file 3), which is also derived from pyruvate (Fig. 1).

RHA detected several other minor influences of $M A E 1$ on traits that were not found by QTL mapping. The MTF2621 allele of the gene leads to a slightly higher production of 2-phenylethanol by a factor of 1.18 (Additional file 3). Mae1 was found to interact with Aro1 [44], an enzyme catalyzing several steps of the chorismate pathway leading to the synthesis of aromatic amino acids, such as phenylalanine [45]. In addition, the MTF2621 allele of Mae1 leads to a decrease of several acetate esters and medium chain fatty acids up to a factor of 0.8 (Fig. 4 and Additional file 3) and to an increase in the extracellular concentration of acetate by a factor of 1.28 (Additional file 3). These effects are consistent with the fact that Mae1 physically interacts with Acc1 [44], an acetyl-CoA carboxylase that is involved in the regulation of acetyl-CoA and in the biosynthesis of medium and long chain fatty acids $[46,47]$.
The gene AGP1, which encodes a low affinity amino acid permease for asparagine and glutamine [48], was validated in QTL chr3@26.1 with an influence on the formation of 2-methylpropanoic acid. The two allelic variants of AGP1 differ in 8 non-synonymous SNPs (Table 4), of which three lie in cytoplasmic domains of the protein and 5 in transmembrane domains. Another SNP is located in the 1000-bp upstream region of the gene, affecting the predicted binding motif for Ume6 (Additional file 4). The hemizygote carrying the MTF2621 allele of the gene shows a formation of 2-methylpropanol, 2-methylpropyl acetate, 2-methylpropanoic acid and ethyl 2-methylpropanoate increased by a factor of 1.26-1.32 (Fig. 4). Agp1 was found to transport valine to a lower extent [48]. Valine can be degraded to $\alpha$-ketoisovalerate and then to 2-methylpropanol and 2-methylpropanoic acid by the Ehrlich pathway (Fig. 4). We hypothesize that the reported SNPs lead to higher affinity of the MTF2621 allele of Agp1 for valine, leading to a higher level of this amino acid in the cell. Another possible explanation is a different influence of the alleles on the transport of glutamine, which is important for the transamination of $\alpha$-keto acids in the cell. In this scenario, a reduced intracellular level of glutamine could lead to a decreased transamination of $\alpha$ ketoisovalerate, which can therefore be degraded to 2methylpropanol and 2-methylpropanoic acid. While this would also affect the transamination of other $\alpha$-keto acids and therefore the production of several higher alcohols or fusel acids, a significant, but small, influence of $A G P 1$ could only be additionally detected on the production of 2-phenylethanol.

In the same QTL (chr3@26.1), the variants of ILV6 did not show significant differences in the formation of 2methylpropanoic acid, but they did in the formation of the related higher alcohol 2-methylpropanol. Ilv6 is a regulatory subunit of the acetolactate synthase Ilv2, which catalyzes the first step of valine and leucine biosynthesis [49]. The allelic variants of ILV6 differ in two non-synonymous SNPs (Table 4). SNP L4S lies in the Nterminal signal peptide domain of the protein, whereas SNP P56A is within a non-cytoplasmic domain. Another SNP is located in the 1000-bp upstream region and causes a loss of the predicted binding motifs for Msn2, Msn4, Nrg1 and Rph1 in strain MTF2621 (Additional file 4). The MTF2621 allele of ILV6 leads to an increase in the formation of 2-methylpropanol and 3-methylbutanol by a factor of 1.24 (Fig. 4). Therefore, we can hypothesize that the MTF2621 allele of ILV6 stimulates a higher synthesis rate of acetolactate, which could result in higher synthesis of $\alpha$-ketoisovalerate, including its degradation products.

\section{The formation of propanol is influenced by Alp1 and Nrg1}

We assessed the three partly interacting genomic regions that were detected with the single, double and multiple 
QTL mapping to affect the production of propanol and related compounds (Table 3). NRG1 and ALP1 were validated in QTL chr4@177.5 and QTL chr14@43.9, respectively. As no clear candidate gene was identified in QTL chr12@226.9, we assessed the whole region by RHA; however, no significant impact could be detected for the production of propanol or propyl acetate. The QTL is likely to interact with chr4@177.5, and the negative validation of chr12@226.9 might indicate a possible epistatic interaction. Furthermore, chr12@226.9 is the weakest QTL of the three assessed loci, with an LOD score of 4.08 (Table 1), which could have hindered the validation.

Propanol and propanoic acid derive from the decarboxylation of $\alpha$-ketobutyrate and the oxidation or reduction of the resulting propionaldehyde [50]. $\alpha-$ Ketobutyrate is produced from the transamination of threonine, which is taken up from the medium as a nitrogen source or can be metabolized from pyruvate via aspartate through the amino acid pathway (Fig. 5). It was shown, however, that the formation of propanol is

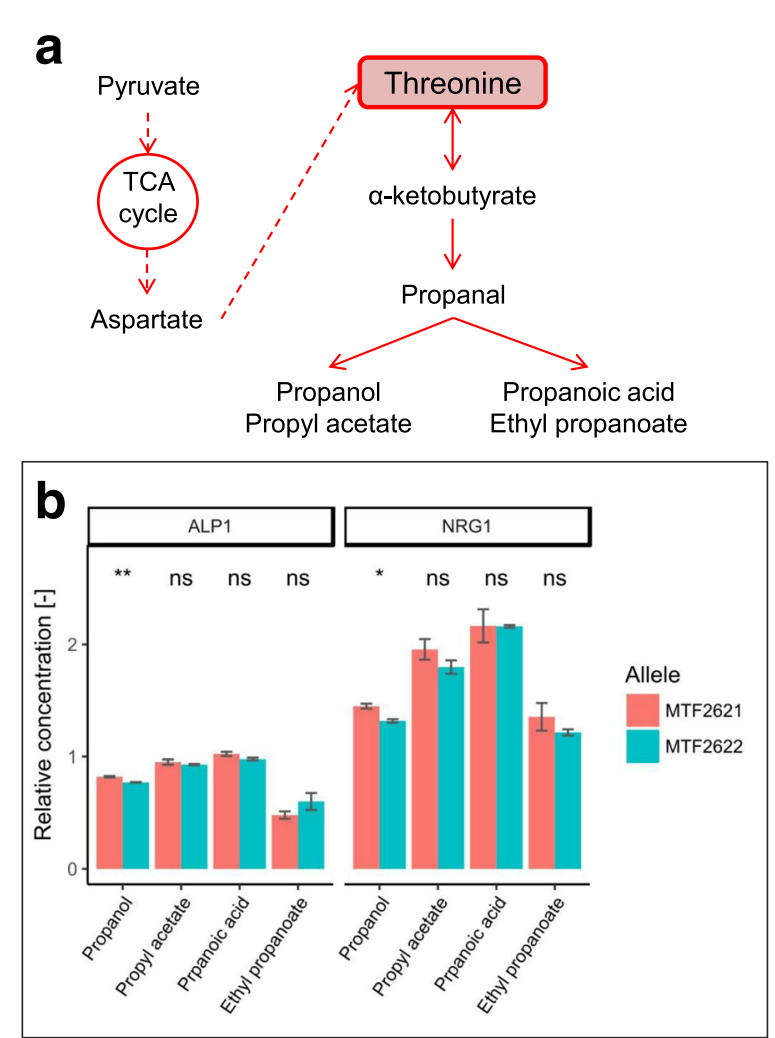

Fig. 5 Effect of validated variants on propanol formation. Simplified synthesis pathway of fermentative aromas connected to threonine metabolism (a). Allelic effect of the involved enzymes Alp1 and $\mathrm{Nrg} 1$ on the formation of volatiles derived from a-ketobutyrate as determined by RHA (b). Concentrations are given in relation to the heterozygote of the parental strains MTF2621 and MTF2622. ( $p$-value: ns (not significant) $\left.>0.05,{ }^{*} \leq 0.05,{ }^{* *} \leq 0.01\right)$ mainly limited to the beginning of wine fermentation when nitrogen is present in the must and is dependent on the initial amount of available nitrogen [51].

The protein Nrg1 is a transcriptional regulator of glucose repressed genes $[52,53]$ and mediates a set of stress responsive genes [54]. The parental allelic variants of NRG1 differ in two non-synonymous SNPs (Table 4), which are both located in the transcriptional repressor protein "yy" domain. The MTF2621 variant of the gene leads to an increase in propanol production by a factor of 1.10 , whereas no significant effect could be detected in the formation of related compounds (Fig. 5). The repressive function of $\mathrm{Nrg} 1$ is inhibited by Snf1; therefore, it is suspected to have a role in the response to nitrogen limitation [55]. Furthermore, Nrg1 was found to influence the expression of $B A T 1$, a mitochondrial aminotransferase involved in branched amino acid synthesis and Ehrlich pathway catabolism [56]. With regard to this finding, we propose that the allelic variants of $\mathrm{Nrg} 1$ show a different response to nitrogen limitation, which affects the expression of BAT1, leading to a lower transamination rate of valine, leucine and isoleucine taken up from the medium. In this scenario, the overall availability of nitrogen for metabolism would be influenced, which therefore influences the synthesis of propanol.

The gene ALP1 encodes a permease for cationic amino acids $[57,58]$. The parental variants differ in one nonsynonymous SNP (Table 4), which is located in a transmembrane domain. The MTF2621 variant increases the production of propanol by a factor of 1.07 (Fig. 5). We can suggest that this variant of Alp1 leads to an increased uptake of amino acids from the medium at the beginning of the fermentation, which explains higher propanol formation. This hypothesis is supported by a significant decrease in fermentative aromas derived from $\alpha$-ketoisovalerate and $\alpha$-ketoisocaproate for the MTF2621 allele of the gene (Fig. 4). The opposite correlation is reported in the literature, in which a lower overall intracellular concentration of nitrogen leads to a higher level of fermentative aroma production due to a lower transamination rate of $\alpha$-keto acids derived from central carbon metabolism [59, 60].

\section{Conclusion}

In this study, we confirm the potential of QTL analysis for deciphering the impact of genetic variation on the production of volatile metabolites by Saccharomyces cerevisiae during alcoholic fermentation. We were able to enlarge the analytical power of the approach compared to previous studies by using a comparatively large number of 130 segregants originating from a cross of two wine strains and by increasing the recombination rate of the segregants. This approach enabled us to perform single and multiple QTL mapping strategies, 
leading to the detection of 65 QTLs with an influence on the formation of volatile metabolites, the production of extracellular main metabolites and general fermentation parameters. Our results confirm that multiple QTL mapping offers the possibility to detect additional, particularly minor loci. We were furthermore able to detect interacting QTLs for three evaluated traits, i.e., the formation of ethyl lactate, ethyl octanoate and propanol. However, it could be seen that an even larger number of segregants is required for a thorough and significant determination of QTL interactions.

We validated 13 genes in 9 QTLs, and of these genes, five (AGP1, ALP1, FAS1, ILV6 and LEU9) have well described roles in metabolic pathways leading to yeast fermentative aroma formation. We could confirm their contribution to volatile production and characterized allelic variants that explain variations in these traits between the parent strains. Furthermore, the previously described fructophilic character of the MTF2621 allele of $H X T 3$ was confirmed in this study. For the other 7 validated genes (AGP2, IXR1, MAE1, NRG1, RGS2, $R G T 1$ and SIR2), we revealed contributions to the formation of fermentative aromas that were not previously reported. The fact that 5 of the 12 validated genes involved in volatile formation have broad regulatory functions on gene expression reveals the significant role of gene regulation in fermentative aroma production. These results demonstrate that QTL mapping is an effective and advisable approach for detecting the impact of globally acting genes on individual traits.

In summary, our findings of QTLs, their interactions and underlying gene variants emphasize the complexity of yeast fermentative aroma formation and provide the most extensive analysis of the links between genetic variation and the fermentative production of sensorial important volatiles to date. The results of this study will lead to the improvement of commercial $S$. cerevisiae starter cultures for the production of fermented food and beverages by non-GMO methods, such as marker-assisted breeding. As many of the described secondary metabolites are additionally used as biofuel additives or building blocks for chemical syntheses, improved knowledge about allelic variation may also open paths for improving strains in a wide range of biotechnological applications.

\section{Methods}

Media

Yeast was cultured at $28{ }^{\circ} \mathrm{C}$ in yeast extract peptone dextrose (YPD) media containing $10 \mathrm{~g} / \mathrm{L}$ yeast extract, $20 \mathrm{~g} / \mathrm{L}$ peptone and $20 \mathrm{~g} / \mathrm{L}$ glucose. Solid YPD media contained $1.5 \%$ agar. Selective YPD media containing $200 \mu \mathrm{g} / \mathrm{mL}$ geneticin (G418), $200 \mu \mathrm{g} / \mathrm{mL}$ nourseothricin (clonNAT) or $200 \mu \mathrm{g} / \mathrm{mL}$ hygromycin B were used.
Wine fermentations were carried out in synthetic must (SM) described by Bely et al. (1990) [61]. The medium contains glucose and fructose (each $100 \mathrm{~g} / \mathrm{L}$ ) and assimilable nitrogen $(200 \mathrm{mg} / \mathrm{L})$ in the form of ammonium and free amino acids, which mimics the nitrogen content of standard grape juice.

\section{Yeast strains}

The S. cerevisiae strains 4CAR1 and T73 exhibit different needs for nitrogen during wine fermentation, which may indicate different formations of aromas associated with nitrogen metabolism. The requirement was previously estimated using an approach based on the addition of nitrogen to keep the $\mathrm{CO}_{2}$ production rate constant during limitation of this substrate. In comparison to strain 4CAR1, strain T73 showed a higher need for nitrogen [22; strain T73 is coded as MTF1782 in this study]. The strain T73 belongs to the phylogenetic clade of wine strains, whereas strain 4CAR1 belongs to the group of champagne strains (Additional file 5), which originated through crossings between strains of the wine clade and the flor clade [28]. For the presented study, haploid spores of these strains were used, coded here as MTF2621 (haploid spore of strain 4CAR1 [ $\left.\triangle H O:: N e o^{\mathrm{r}}\right]$ ) and MTF2622 (haploid spore of strain T73 [ $\left.\Delta H O:: N a t^{\mathrm{r}}\right]$ ). The same spores have been previously used by Brice et al. (2014) to map QTLs influencing nitrogen requirement during fermentation [16, coded as MTF1782-B1 and MTF2029-C5 in this study].

\section{Generation of F2-segregants}

The strains MTF2621 and MTF2622 were mated to form a zygote, which was selected on YPD-agar containing G418 and clonNAT. The zygote was then sporulated in liquid sporulation media using the protocol of Codon et al. (1995) [62]. The resulting tetrads were dissected into single spores to obtain the F1-generation using a Singer MSM 400 workstation (Singer Instruments). In most cases, only one spore per tetrad was taken for further experiments to increase genomic independence among the spores. The antibiotic resistance of the obtained spores was determined by growth assay on YPD-agar plates containing G418 or clonNAT. Two spores with different antibiotic properties were mated, and the formed zygotes were subsequently selected on YPD-agar containing G418 and clonNAT. These zygotes were sporulated and dissected again. In total, 130 single spores from the F2-generation were used for this study.

\section{Genotyping of strains}

The genomic DNA of all 130 F2-segregants and both parent strains was isolated using the MasterPure ${ }^{\mathrm{Tm}}$ Yeast DNA Purification Kit (epicentre) according to the 
protocol. The purity of the DNA was measured using a NanoDrop ${ }^{\text {Ta }}$ device (Thermo Fisher Scientific), and the concentration was determined by Qubit ${ }^{\mathrm{Tm}}$ fluorometric quantification (Thermo Fisher Scientific). The DNA samples were then used for sequencing using Illumina technology (HiSeq 2500, paired end, $2 \times 100 \mathrm{bp}$, sequencing platform Genotoul in Toulouse, France) at a sequencing depth of 20- to 80-fold. For each library, low-quality reads were processed and filtered with the FASTX Toolkit v0.0.13.2 and TRIMMOMATIC v0.30 [63] using a quality threshold of 20. First, reads were aligned to the S288C reference genome (release R64-1-1) using BWA v0.6.2 [64]. Once the reads were mapped, consensus genotype calling was performed using the tools available in the SAMtools package [65]. The global set of variants obtained in VCF format contained 18,155 biallelic variant positions with a genotyping quality greater than 100. The effect of SNPs on putative transcription factor binding sites was analyzed using YEASTRACT (release 2017; [66]). For the location of SNPs in annotated protein domains, information available in the Saccharomyces Genome Database (http://www.yeastgenome.org) was used. The initial variant set was filtered to ensure a minimum spacing of $2.0 \mathrm{~kb}$ between SNPs. This resulted in a genotyping variant dataset of 3727 SNP markers (Additional file 6). To increase the meaningfulness of the analysis, four strains with the most ambiguous markers were excluded. One strain was excluded because it was too close in genomic proximity to another segregant. This left a population of $125 \mathrm{~F} 2$-segregants for statistical analyses.

\section{Phenotyping of strains}

Segregants were fermented in duplicate with the parent strains as controls. The strains were grown overnight in $50 \mathrm{~mL}$ of YPD media. The cell density was determined using a Multisizer ${ }^{\mathrm{TM}} 3$ Coulter Counter (Beckman Coulter). Sterilized 300-mL glassware mini fermenters were filled with $280 \mathrm{~mL}$ of SM200 and closed with an air lock. The fermenters were inoculated to a cell density of $1 \times 10^{6}$ cells $/ \mathrm{mL}$, weighed and left at $24{ }^{\circ} \mathrm{C}$ under stirring (300 rpm).

To determine the concentration of aroma compounds, a sample was taken when approx. $80 \%$ of the sugars were depleted. This corresponded to $67.9-75 \mathrm{~g} / \mathrm{L}$ produced $\mathrm{CO}_{2}$ and was determined by weighting the fermenters regularly to draw the weight decrease caused by the release of $\mathrm{CO}_{2}$. Volatiles were extracted with dichloromethane according to the method described by Rollero et al. (2015) [67]. The concentrations of fermentative aromas were measured via GC/MS on full scan mode using a DB-WAX $60 \mathrm{~m}$ GC column. Thirty-four compounds were quantified using internal deuterated standards. In addition, the concentrations of extracellular metabolites after $80 \%$ of the fermentation were measured using HPLC (REZEX $^{\mathrm{mm}}$ ROA-Organic Acid $\mathrm{H}+(8 \%), 0.005 \mathrm{M} \mathrm{H}_{2} \mathrm{SO}_{4}$ ).

\section{QTL mapping}

The data obtained from phenotyping and genotyping were used to identify QTLs in the genome of yeast strains that influence the formation of volatile secondary metabolites during wine fermentation. Furthermore, QTLs influencing fermentation parameters, substrate consumption and the production of extracellular main metabolites were examined. The statistical analyses were performed using the programming language $\mathrm{R}$ v3.2.3 (www.r-project.org) with the R/qtl v1.40-8 and R/eqtl v1.1-7 libraries [68]. QTL mapping was performed with two different phenotype models, the normal model using Haley-Knott regression and a non-parametric analysis, resulting in logarithm of odds (LOD) scores for each marker and pseudo-marker every $2.5 \mathrm{cM}$ (interval mapping method). An interval estimate of the location of each QTL was obtained as the 1-LOD support interval, the region in which the LOD score is within 1 unit of the peak LOD score. If the same locus was detected with both models, the results with the higher LOD score were selected. A twodimensional, two-QTL scan was performed using the function scantwo. Multiple QTL mapping was performed twice with the function stepwiseqtl, once with strictly additive models and once with models that allowed for interactions. The limit of detected QTLs was set to 5 . Newly detected QTL positions were counted when the LOD scores of models including these loci were higher than the added LOD score penalties of combining all loci of the respective model. For each method used, individual LOD score thresholds for a false discovery rate of 0.05 were determined with 1000 permutations. QTL mapping results for single traits were grouped as common QTL regions if their peaks were less than $10 \mathrm{cM}$ apart. Proposed models of interaction were further assessed with the function fitqtl. The support of individual terms was evaluated by dropping each QTL from the proposed model, one at a time, and comparing the resulting models to the full model.

\section{Reciprocal hemizygosity analysis}

Validation of found QTLs was performed using reciprocal hemizygosity analysis (RHA) [12]. QTLs were either evaluated as a whole region or single genes with a potential influence on the trait were tested. For the deletion of selected regions, the parent strains were mated to form the heterozygote. Subsequently, one allele of the region was deleted randomly by homologous recombination with a disruption cassette containing the hygromycin B resistance gene $\left(h p h^{\mathrm{r}}\right)$ that was obtained by PCR of the plasmid pAG32 (addgene) with the primers del_(QTL)_fw and del_(QTL)_rv (Additional file 7). Positive integration was 
selected by plating the transformed cells on YPD-agar plates containing hygromycin $\mathrm{B}$. Correct deletion of the region was verified by PCR using primer test_(QTL)_fw that binds upstream of the deleted region and primer Hygro_rv that binds within the deletion cassette. The remaining allele of the QTL was identified by allelic PCR using primer test_(QTL)_fw that binds upstream of a selected gene in the hemizygous region and primers tal_(QTL)_1 or tal_(QTL)_2 that bind at a SNP position within the same gene.

For the deletion of single genes, the sequences were deleted in both parent strains by homologous recombination with a disruption cassette containing the hygromycin B resistance gene $\left(h p h^{\mathrm{r}}\right)$ that was obtained by PCR of the plasmid pAG32 with the primers del_(GENE)_fw and del_(GENE)_rv. Positive integration was selected by plating the transformed cells on YPD-agar plates containing hygromycin $\mathrm{B}$. Correct deletion of the gene was verified by PCR using primer test_(GENE)_fw that binds upstream of the deleted gene and primer Hygro_rv that binds within the deletion cassette. Deleted parent strains were subsequently mated with the opposite undeleted parent to form a heterozygote that is hemizygous for the target gene.

Hemizygous constructions were phenotyped in triplicate. The significance of the influence of an allelic target region or gene variant on the trait was evaluated by student's $t$ test. If the impact of a variant on several traits was tested, $p$-values were not adjusted for multiple comparisons.

\section{Additional files}

Additional file 1: Additional phenotypic information. Concentrations of determined secondary metabolites produced by the parental strains used in this study with trait variety among the segregant population given as interquartile range (IQR) and heritability of evaluated traits. (XLSX $21 \mathrm{~kb}$ )

Additional file 2: Phenotype distributions among population. Distribution of evaluated traits for QTL mapping among all 130 F2-segregants of the study. The position of parental cells within the population is marked in red for MTF2621 and in green for MTF2622. (PDF $12 \mathrm{~kb}$ )

Additional file 3: Additionally detected allelic effects of the described enzymes as determined by RHA. Allelic effect of the sugar transporters Hxt3, Hxt6 and Hxt7 on the G/F ratio (A). Allelic effect of the enzymes Mae1 and Sir2 on the acetate yield (B). Allelic effect of the enzymes Agp1 and Mae1 on the production of 2-phenylethanol (C). Allelic effect of Mae1 on the formation of ethyl lactate (D) and fatty acids and fatty acid ethyl esters $(\mathbf{E})$. Concentrations are given in relation to the heterozygote of the parental strains MTF2621 and MTF2622. ( $p$-value: ns (not significant) $\left.>0.05,{ }^{*} \leq 0.05,{ }^{*} \leq 0.01,{ }^{* *} \leq 0.001\right)$. (PDF $\left.9 \mathrm{~kb}\right)$

Additional file 4: SNPs in predicted regulatory binding sites of validated genes. Detected SNPs in the 1000-bp upstream region of evaluated target genes that affect binding motifs for regulatory proteins as predicted with YEASTRACT [66]. Comparison of the strains MTF2621 and MTF2622 with the S. cerevisiae reference strain S288C. (XLSX $242 \mathrm{~kb}$ )

Additional file 5: Genomic background of parent strains. Location of the S. cerevisiae strains used in this study, MTF2621 (4CAR1) and MTF2622 (T73), within the genotypic subgroups of champagne strains (light green lines) and wine strains (dark green lines). Phylogenetic tree constructed with data from and as described by Legras et al. (2007) [69]. (PDF $2648 \mathrm{~kb}$ )
Additional file 6: Marker map. Graphic representation of marker positions that were used for linkage analysis. (TIF $8 \mathrm{~kb}$ )

Additional file 7: Table of primers used in this study. (XLSX 295 kb)

\section{Abbreviations}

FAS: Fatty acid synthetase; LOD: logarithm of odds; PCA: Principal component analysis; QTL: Quantitative trait locus; RHA: Reciprocal hemizygosity analysis; SM: Synthetic must; SNP: Single-nucleotide polymorphism; YPD: Yeast extract peptone dextrose

\section{Acknowledgements}

We are grateful to Bruno Blondin for his contribution to the design of the QTL strategy. We thank Anna Hagstrom for her technical help in the construction of hemizygotes. CB thanks the program CONICYT Postdoctorado / FONDECYT 3150159 for support through a postdoctoral grant.

\section{Funding}

The research leading to these results has received funding from the People Programme (Marie Curie Actions) of the European Union's Seventh Framework Programme FP7/2007-2013/ under REA grant agreement $n^{\circ}$ 606795, project acronym: YEASTCELL. The funding body was not involved in the design of the study, in the collection, analysis and interpretation of data or in writing the manuscript.

\section{Availability of data and materials}

Genome sequencing data generated during the current study is available from NCBI under bioproject number PRJNA433287; microsatellite-tree data, SNP data, marker map and phenotypic data set are available from the Dryad Digital Repository: https://doi.org/10.5061/dryad.ps441

\section{Authors' contributions}

ME conducted the experiments, contributed to the linkage analysis and wrote the manuscript. IS established and performed the linkage analysis. CB contributed to the selection of parent cells and generation of F2-segregants. CC contributed to the phenotyping of strains. JLL analyzed the genotyping data. SD conceived and planned the study, with contribution of CC and JLL. All authors revised the manuscript and read and approved the final manuscript.

Ethics approval and consent to participate Not applicable.

\section{Consent for publication}

Not applicable.

\section{Competing interests}

The authors declare that they have no competing interest.

\section{Publisher's Note}

Springer Nature remains neutral with regard to jurisdictional claims in published maps and institutional affiliations.

\section{Author details}

${ }^{1}$ SPO, INRA, SupAgro, Université de Montpellier, F-34060 Montpellier, France. ${ }^{2}$ MISTEA, INRA, SupAgro, F-34060 Montpellier, France.

Received: 18 September 2017 Accepted: 20 February 2018

Published online: 01 March 2018

\section{References}

1. Romano P, Fiore C, Paraggio M, Caruso M, Capece A. Function of yeast species and strains in wine flavour. Int J Food Microbiol. 2003;86:169-80.

2. Robinson AL, Boss PK, Heymann H, Solomon PS, Trengove RD. Influence of yeast strain, canopy management, and site on the volatile composition and sensory attributes of cabernet sauvignon wines from Western Australia. J Agric Food Chem. 2011;59:3273-84.

3. Cordente AG, Curtin CD, Varela C, Pretorius IS. Flavor-active wine yeasts. Appl Microbiol Biotechnol. 2012;96:601-18.

4. Lambrechts MG, Pretorius IS. Yeast and its importance to wine aroma - a review. South African J Enol Vitic. 2000;21:97-129. 
5. Nykänen L, Suomalainen H. Aroma of beer, wine and distilled alcoholic beverages. Berlin: Springer Science \& Business Media; 1983.

6. Nykänen L. Formation and occurrence of flavor compounds in wine and distilled alcoholic beverages. Am. J. Enol. Vitic. 1986;37:84-96.

7. Mason AB, Dufour J. Alcohol acetyltransferases and the significance of ester synthesis in yeast. Yeast. 2000;16:1287-98.

8. Saerens SMG, Verstrepen KJ, Van Laere SDM, Voet ARD, Van Dijck P, Delvaux FR, et al. The Saccharomyces cerevisiae EHT1 and EEB1 genes encode novel enzymes with medium-chain fatty acid ethyl ester synthesis and hydrolysis capacity. J Biol Chem. 2006;281:4446-56.

9. Rossouw D, Jacobson D, Bauer FF. Transcriptional regulation and the diversification of metabolism in wine yeast strains. Genetics. 2012;190:251-61.

10. Steyer D, Ambroset C, Brion C, Claudel P, Delobel P, Sanchez I, et al. QTL mapping of the production of wine aroma compounds by yeast. BMC Genomics. 2012;13:573.

11. Deutschbauer AM, Davis RW. Quantitative trait loci mapped to singlenucleotide resolution in yeast. Nat Genet. 2005;37:1333-40.

12. Steinmetz LM, Sinha H, Richards DR, Spiegelman Jl, Oefner PJ, McCusker JH, et al. Dissecting the architecture of a quantitative trait locus in yeast. Nature. 2002;416:326-30.

13. Marullo $P$, Aigle M, Bely M, Masneuf-Pomarède I, Durrens P, Dubourdieu D, et al. Single QTL mapping and nucleotide-level resolution of a physiologic trait in wine Saccharomyces cerevisiae strains. FEMS Yeast Res. 2007;7:941-52.

14. Ambroset C, Petit M, Brion C, Sanchez I, Delobel P, Guérin C, et al. Deciphering the molecular basis of wine yeast fermentation traits using a combined genetic and genomic approach. G3 (Bethesda). 2011;1:263-81.

15. Salinas F, Cubillos FA, Soto D, Garcia V, Bergström A, Warringer J, et al. The genetic basis of natural variation in oenological traits in Saccharomyces cerevisiae. PLoS One. 2012;7:e49640.

16. Brice C, Sanchez I, Bigey F, Legras J-L, Blondin B. A genetic approach of wine yeast fermentation capacity in nitrogen-starvation reveals the key role of nitrogen signaling. BMC Genomics. 2014;15:495.

17. Noble J, Sanchez I, Blondin B. Identification of new Saccharomyces cerevisiae variants of the MET2 and SKP2 genes controlling the sulfur assimilation pathway and the production of undesirable sulfur compounds during alcoholic fermentation. Microb Cell Fact. 2015;14:68

18. Martí-raga M, Mas A, Beltran G. Genetic causes of phenotypic adaptation to the second fermentation sparkling wines in. G3 (Bethesda). 2017;7:399.

19. Bloom JS, Kotenko I, Sadhu MJ, Treusch S, Albert FW, Kruglyak L. Genetic interactions contribute less than additive effects to quantitative trait variation in yeast. Nat Commun. 2015;6:8712.

20. García-Ríos E, Morard M, Parts L, Liti G, Guillamón JM. The genetic architecture of low-temperature adaptation in the wine yeast Saccharomyces cerevisiae. BMC Genomics. 2017;18:159.

21. Arends $D$, Prins $P$, Jansen RC, Broman KW. R/QTL: high-throughput multiple QTL mapping. Bioinformatics. 2010;26:2990-2.

22. Brice C, Sanchez I, Tesnière C, Blondin B. Assessing the mechanisms responsible for differences between nitrogen requirements of Saccharomyces cerevisiae wine yeasts in alcoholic fermentation. Appl Environ Microbiol. 2014;80:1330-9.

23. Brem RB, Yvert G, Clinton R, Kruglyak L. Genetic dissection of transcriptional regulation in budding yeast. Science. 2002;296:752-5.

24. Den Abt T, Souffriau B, Foulquié-Moreno MR, Duitama J, Thevelein JM. Genomic saturation mutagenesis and polygenic analysis identify novel yeast genes affecting ethyl acetate production, a non-selectable polygenic trait. Microb Cell. 2016;3:159-75.

25. Rossouw D, Næs T, Bauer FF. Linking gene regulation and the exometabolome: a comparative transcriptomics approach to identify genes that impact on the production of volatile aroma compounds in yeast. BMC Genomics. 2008;9:530.

26. Elbing K, Larsson C, Bill RM, Albers E, Snoep JL, Boles E, et al. Role of hexose transport in control of glycolytic flux in Saccharomyces cerevisiae. Appl Environ Microbiol. 2004;70:5323-30.

27. Guillaume C, Delobel P, Sablayrolles JM, Blondin B. Molecular basis of fructose utilization by the wine yeast Saccharomyces cerevisiae: a mutated HXT3 allele enhances fructose fermentation. Appl Environ Microbiol. 2007; 73:2432-9.

28. Coi AL, Legras J-L, Zara G, Dequin S, Budroni M. A set of haploid strains available for genetic studies of Saccharomyces cerevisiae flor yeasts. FEMS Yeast Res. 2016;16:fow066.
29. Kolodziej SJ, Penczek PA, Schroeter JP, Stoops JK. Structure-function relationships of the Saccharomyces cerevisiae fatty acid synthase threedimensional structure. J Biol Chem. 1996;271:28422-9.

30. Wenz P, Schwank S, Hoja U, Schüller H-J. A downstream regulatory element located within the coding sequence mediates autoregulated expression of the yeast fatty acid synthase gene FAS2 by the FAS1 gene product. Nucleic Acids Res. 2001;29:4625-32.

31. Schweizer M, Roberts LM, Höltke H-J, Takabayashi K, Höllerer E, Hoffmann B, et al. The pentafunctional FAS1 gene of yeast: its nucleotide sequence and order of the catalytic domains. Mol Gen Genet. 1986;203:479-86.

32. Rine J, Herskowitz I. Four genes responsible for a position effect on expression from HML and HMR in Saccharomyces cerevisiae. Genetics. 1987; 116:9-22.

33. Lin Y, Qi Y, Lu J, Pan X, Yuan DS, Zhao Y, et al. A comprehensive synthetic genetic interaction network governing yeast histone acetylation and deacetylation. Genes Dev. 2008;22:2062-74.

34. Starai VJ, Takahashi H, Boeke JD, Escalante-Semerena JC. Short-chain fatty acid activation by acyl-coenzyme a synthetases requires SIR2 protein function in salmonella enterica and Saccharomyces cerevisiae. Genetics. 2003;163:545-55.

35. Casatta N, Porro A, Orlandi I, Brambilla L, Vai M. Lack of Sir2 increases acetate consumption and decreases extracellular pro-aging factors. Biochim. Biophys. Acta (BBA)-molecular cell res. Elsevier. 2013;1833:593-601.

36. Liu B, Larsson L, Caballero A, Hao X, Öling D, Grantham J, et al. The polarisome is required for segregation and retrograde transport of protein aggregates. Cell. 2010;140:257-67.

37. Bloem A, Sanchez I, Dequin S, Camarasa C. Metabolic impact of redox cofactor perturbations on the formation of aroma compounds in Saccharomyces cerevisiae. Appl Environ Microbiol. 2015;82:174-83.

38. Van Roermund CWT, Hettema EH, Van Den Berg M, Tabak HF, Wanders RJA. Molecular characterization of carnitine-dependent transport of acetyl-CoA from peroxisomes to mitochondria in Saccharomyces cerevisiae and identification of a plasma membrane carnitine transporter, Agp2p. EMBO J. 1999;18:5843-52.

39. Schreve JL, Garrett JM. Yeast Agp2p and Agp3p function as amino acid permeases in poor nutrient conditions. Biochem Biophys Res Commun. 2004;313:745-51.

40. Van Roermund CW, Elgersma Y, Singh N, Wanders RJ, Tabak HF. The membrane of peroxisomes in Saccharomyces cerevisiae is impermeable to NAD (H) and acetyl-CoA under in vivo conditions. EMBO J. 1995;14:3480.

41. Aouida M, Texeira MR, Thevelein JM, Poulin R, Ramotar D. Agp2, a member of the yeast amino acid permease family, positively regulates polyamine transport at the transcriptional level. PLoS One. 2013;8:e65717.

42. Boles E, De Jong-Gubbels P, Pronk JT. Identification and characterization of MAE1, the Saccharomyces cerevisiae structural gene encoding mitochondrial malic enzyme. J Bacteriol. 1998;180:2875-82.

43. Umbarger HE. Amino acid biosynthesis and its regulation. Annu Rev Biochem. 1978;47:533-606.

44. Gavin A-C, Aloy P, Grandi P, Krause R, Boesche M, Marzioch M, et al. Proteome survey reveals modularity of the yeast cell machinery. Nature. 2006;440:631-6.

45. Duncan K, Edwards RM, Coggins JR. The pentafunctional arom enzyme of Saccharomyces cerevisiae is a mosaic of monofunctional domains. Biochem J. 1987;246:375-86.

46. Mishina M, Rogquenkamp R, Schweizer E. Yeast mutants defective in acetylcoenzyme a carboxylase and biotin: Apocarboxylase ligase. FEBS J. 1980;111: 79-87.

47. Galdieri L, Vancura A. Acetyl-CoA carboxylase regulates global histone acetylation. J Biol Chem. 2012;287:23865-76.

48. Schreve JL, Sin JK, Garrett JM. The Saccharomyces cerevisiae YCC5 (YCL025c) gene encodes an amino acid permease, Agp1, which transports asparagine and glutamine. J Bacteriol. 1998;180:2556-9.

49. Cullin C, Baudin-Baillieu A, Guillemet E, Ozier-Kalogeropoulos O. Functional analysis of YCLO9C: evidence for a role as the regulatory subunit of acetolactate synthase. Yeast. 1996;12:1511-8.

50. Hazelwood LA, Daran JM, van Maris AJ, Pronk JT, Dickinson JR. The Ehrlich pathway for fusel alcohol production: a century of research on Saccharomyces cerevisiae metabolism. Appl Environ Microbiol. 2008;74: 2259-66.

51. Mouret JR, Camarasa C, Angenieux M, Aguera E, Perez M, Farines V, et al. Kinetic analysis and gas-liquid balances of the production of fermentative 
aromas during winemaking fermentations: effect of assimilable nitrogen and temperature. Food Res Int. 2014;62:1-10.

52. Zhou H, Winston F. NRG1 is required for glucose repression of the SUC2 and GAL genes of Saccharomyces cerevisiae. BMC Genet. 2001;2:5.

53. Park SH, Koh SS, Chun JH, Hwang HJ, Kang HS. Nrg1 is a transcriptional repressor for glucose repression of STA1 gene expression in Saccharomyces cerevisiae. Mol Cell Biol. 1999;19:2044-50.

54. Vyas VK, Berkey CD, Miyao T, Carlson M. Repressors Nrg1 and Nrg2 regulate a set of stress-responsive genes in Saccharomyces cerevisiae. Eukaryot Cell. 2005:4:1882-91.

55. Kuchin S, Vyas VK, Carlson M. Snf1 protein kinase and the repressors Nrg1 and Nrg2 regulate FLO11, haploid invasive growth, and diploid pseudohyphal differentiation. Mol Cell Biol. 2002;22:3994-4000.

56. Costanzo M, Baryshnikova A, Bellay J, Kim Y, Spear ED, Sevier CS, et al. The genetic landscape of a cell. Science. 2010:327:425-31.

57. Sychrova H, Chevallier M. APL1, a yeast gene encoding a putative permease for basic amino acids. Yeast. 1994;10:653-7.

58. Regenberg B, Düring-Olsen L, Kielland-Brandt MC, Holmberg S. Substrate specificity and gene expression of the amino-acid permeases in Saccharomyces cerevisiae. Curr Genet. 1999;36:317-28.

59. Oshita K, Kubota M, Uchida M, Ono M. Clarification of the relationship between fusel alcohol formation and amino acid assimilation by brewing yeast using 13C-labeled amino acid. Proc Congr Brew Conv. Oxford: Cong., Brussels, IRL Press; 1995. p. 387-394.

60. Vilanova M, Ugliano M, Varela C, Siebert T, Pretorius IS, Henschke PA. Assimilable nitrogen utilisation and production of volatile and non-volatile compounds in chemically defined medium by Saccharomyces cerevisiae wine yeasts. Appl Microbiol Biotechnol. 2007;77:145-57.

61. Bely M, Sablayrolles J-M, Barre P. Automatic detection of assimilable nitrogen deficiencies during alcoholic fermentation in oenological conditions. J Ferment Bioeng. 1990;70:246-52.

62. Codon AC, Gasent-Ramirez JM, Benitez T. Factors which affect the frequency of sporulation and tetrad formation in Saccharomyces cerevisiae baker's yeasts. Appl Environ Microbiol. 1995;61:630-8.

63. Bolger AM, Lohse M, Usadel B. Trimmomatic: a flexible trimmer for Illumina sequence data. Bioinformatics. 2014;30:2114-20.

64. Li H, Durbin R. Fast and accurate short read alignment with burrowswheeler transform. Bioinformatics. 2009;25:1754-60.

65. Li H, Handsaker B, Wysoker A, Fennell T, Ruan J, Homer N, et al. The sequence alignment/map format and SAMtools. Bioinformatics. 2009;25:2078-9.

66. Teixeira MC, Monteiro PT, Guerreiro JF, Gonçalves JP, Mira NP, dos Santos SC, et al. The YEASTRACT database: an upgraded information system for the analysis of gene and genomic transcription regulation in Saccharomyces cerevisiae. Nucleic Acids Res. 2013;42:D161-6.

67. Rollero S, Bloem A, Camarasa C, Sanchez I, Ortiz-Julien A, Sablayrolles J-M, et al. Combined effects of nutrients and temperature on the production of fermentative aromas by Saccharomyces cerevisiae during wine fermentation. Appl Microbiol Biotechnol. 2015;99:2291.

68. Broman KW, Wu H, Sen Ś, Churchill GA. R/QTL: QTL mapping in experimental crosses. Bioinformatics. 2003;19:889.

69. Legras J, Merdinoglu D, Cornuet J, Karst F. Bread, beer and wine: Saccharomyces cerevisiae diversity reflects human history. Mol Ecol. 2007;16: 2091-102.

\section{Submit your next manuscript to BioMed Central and we will help you at every step:}

- We accept pre-submission inquiries

- Our selector tool helps you to find the most relevant journal

- We provide round the clock customer support

- Convenient online submission

- Thorough peer review

- Inclusion in PubMed and all major indexing services

- Maximum visibility for your research

Submit your manuscript at www.biomedcentral.com/submit

) Biomed Central 